\title{
Good vibrations: living with the motions of our unsettled planet
}

\author{
Tamsin Badcoe ${ }^{1}$, Ophelia Ann George ${ }^{2}$, Lucy Donkin ${ }^{3}$, Shirley Pegna ${ }^{4}$, and John Michael Kendall ${ }^{2, a}$ \\ ${ }^{1}$ Department of English, University of Bristol, Bristol, UK \\ ${ }^{2}$ School of Earth Sciences, University of Bristol, Bristol, UK \\ ${ }^{3}$ Department of History of Art, University of Bristol, Bristol, UK \\ ${ }^{4}$ Sound Artist, Bristol, UK \\ ${ }^{a}$ now at: Department of Earth Sciences, University of Oxford, Oxford, UK
}

Correspondence: Ophelia Ann George (ophelia.george@bristol.ac.uk)

Received: 2 June 2020 - Discussion started: 17 June 2020

Revised: 7 September 2020 - Accepted: 29 September 2020 - Published: 6 November 2020

Abstract. By its very nature Earth is unsettled and in continual motion. Earthquakes and volcanoes are an expression of the convective motions of the planet, and our existence on Earth is a consequence of this tectonic activity. Yet, as humans, we often struggle to understand our role in relation to such unpredictable natural phenomena and use different methods to attempt to find order in nature's chaos. In dwelling on the surface of our "unsettled planet", we adapt and live with a range of ground vibrations, both natural and anthropogenic in origin. Our project, funded by the University of Bristol's Brigstow Institute, seeks to explore how we perceive and understand the shaky ground we live on, using an interdisciplinary approach that brings together the Earth sciences, the history of art and literature, and performance art. Inspired by historical commentary in the aftermath of large earthquakes, which frequently notes the unscheduled ringing of church bells excited by the shaking around them, we reflect on how these purported unscheduled bell-ringing events were caused not only by near earthquakes but also by distant incidents. To investigate this phenomenon, we installed a state-of-the-art broadband seismometer in the Wills Memorial Building tower to record how Great George (the tower bell) responds to the restless world around him. The installed seismometer has been recording activity around and within the tower on a near-continuous basis between lateMarch 2018 and January 2019. Here, we present the signals recorded by the seismometer as Great George overlooks the hustle and bustle of the city around him and investigate how connected we are to our unsettled planet, even from our tectonically quiet setting in Bristol. We find that the seismometer not only shows the ebb and flow of activity in and around
Bristol but also registers earthquakes from as nearby as Lincolnshire, UK, or as far away as Fiji, halfway around the world. In order to contextualize our findings, our project also considers what determines how people have responded to earth-shaking events, drawing on both historical and recent examples, and looks to contemporary art practice to consider how an awareness of our unsettled planet can be communicated in new ways. The project has led to a number of art installations and performances, and feedback from artists and audiences shows how making art can be used to both investigate our connections with the Earth and to articulate (and even accept) the uncertainties inherent in encountering unstable ground.

\section{Introduction - the Unsettled Planet project}

People live with the ground shaking on a daily basis but when and why we become aware of this is contextual. To varying degrees, our capacity to dwell on the surface of the Earth is shaped by a learned tolerance of vibrations - sometimes benevolent and commonplace and at other times potentially calamitous - beneath and through our spaces of habitation. From the measurable footfall of humans walking along a pedestrian street in Bristol and the locomotion of individual elephants in Kenya to the co-ordinated motion of a stadium crowd and the combined impact of traffic noise, our world reverberates with the forces generated by human, animal and vehicular activity. The resulting vibrations go largely unnoticed as the ground motion that they produce is relatively small and fades into the hustle of everyday life. More at- 
tention grabbing, of course, are the vibrations produced by phenomena such as earthquakes.

Whether large or small, these vibrations provide vital information not only about the settings in which we live but also about the natural world around us and how we react to it. Just as footsteps are easier to discern when made on a creaky floor than they are on solid ground, so too does the setting in which Earth shaking occurs affect our perception of events. The 1985 magnitude- 8 earthquake, $350 \mathrm{~km}$ away from Mexico City, for example, caused significant damage and loss of life. The extent of the damage was due to the nature of the ground beneath the city (Seed et al., 1988). Centuries earlier, as Nichols (2014) observes of the devastating 1755 Lisbon earthquake, "the historic Baixia area on the north side of the Tagus, the seat of government, with narrow streets and timber-built houses, rested on water-saturated alluvial sediment" that "liquefied during the earthquake and lost its bearing strength during the shock waves. Down the coast, Tavira, sitting on limestone met with few casualties". Furthermore, human-induced earthquakes in Lancashire - due to hydraulic fracture stimulation (fracking) - register differently in the public consciousness (Williams et al., 2017) than much larger natural earthquakes in more seismically active regions such as Japan. An earthquake can thus be a disaster for one person, slightly worrying for another and barely perceptible for many more. The factors shaping individual responses might be simply determined by proximity to an earthquake but are more often influenced by other considerations including the underlying geology, local culture, collective memory, a familiarity with the associated phenomena, and the inequalities of disaster management. Living on an unsettled planet such as ours is tolerable for most of the time but at other times can be catastrophic.

This paper offers reflections on an interdisciplinary project that explored the relationship between scales of Earth shaking and thresholds of habituation. A response to the theme of "living well with uncertainty" proposed by the University of Bristol's Brigstow Institute, the project brought together a sound artist and researchers from the arts, humanities and earth sciences at the university. We found ourselves particularly interested in how people react to first-hand experiences with the fact that the ground is not stable or firm. At one extreme, this involved thinking about living in earthquakeprone regions, and at the other, it involved considering how someone from the countryside might find it unsettling to live in a city with heavy traffic vibrations. Indeed, as we discovered, thinking about how people live with the ground shaking daily does not just apply to distant places, rich in seismic activity, poised on a fault line, but can also be used to consider our own located positions, which, for the purposes of the project, took in the steep incline of Park Street and the Wills Memorial Building in Bristol: surely, the epitome of solid ground. Even familiar territory, we found, is constantly on the move, impacted by both our own bodies and by seismic events across the world. In the School of Earth
Sciences, for example, our conversations took place against a background of heavy traffic vibration caused by buses passing by immediately outside the windows of the Wills Memorial Building: vibrations ultimately equivalent to those that might reach Bristol from a distant earthquake. In combining approaches drawn from geophysics, the humanities and the arts, then, we connected different categories of knowledgemaking in order to grasp what is there or what could be there, not only under but also passing through the ground beneath our feet, and made links between what we know and what we imagine. The project focused on the current discourses surrounding controversial issues such as fracking but also looked at how past perceptions of seismic and volcanic hazards have evolved over time. We specifically aimed to probe the effects of seismic vibrations from regions of the Earth that are both near to and far from our relative haven in Bristol and to reflect on how those events are perceived by those around us. Our group aim was to engage with the sounding phenomena around us, thus enabling us to perceive the world in a different and more connected way.

Within our interdisciplinary team of co-authors, we found marked differences in our ways of working. It was easy to recognize this methodological range, but its implications were harder to fathom. We could use labels that corresponded to the badges of our professions - earth sciences, literary and historical studies, artistic practice - but the project asked us to think about our default settings and manner of approaching things. Some of us are more attentive to sounds, some of us to words, some to images, some to things, and some to numbers. Some of us think mainly in decades and centuries, while others in minutes or even in millions of years. We did not strain to find common ground; after all, we have a collective interest in the ground beneath our feet. It was always easy to talk, but this involved a particular kind of conversation, which one participant described as "specialists speaking colloquially". Of course, we are also more than our disciplines. What we each brought to the discussion was dependent on the parts of the Earth's surface with which we are familiar; this was a frame of reference which came partly from professional activities but also personal trajectories, anecdotes, questions, lines from a poem, an image and identities; all of these provided points of connection, but we ultimately found collective stimulus in a bell.

\subsection{Great George and the Wills Memorial Building}

Great George (the bell in the tower of the Wills Memorial Building) became something of an emblem for us in that it offered a fusion of "vibrant matter" and symbolic resonance (Bennett, 2010). As a material object specifically designed and fabricated to resound in a particular way, the bell participates physically in the marking of time but also acts as a reminder of how bells have historically sounded in times of celebration, admonition and mourning. By using the bell as an instrument for registering vibration, whether that caused 


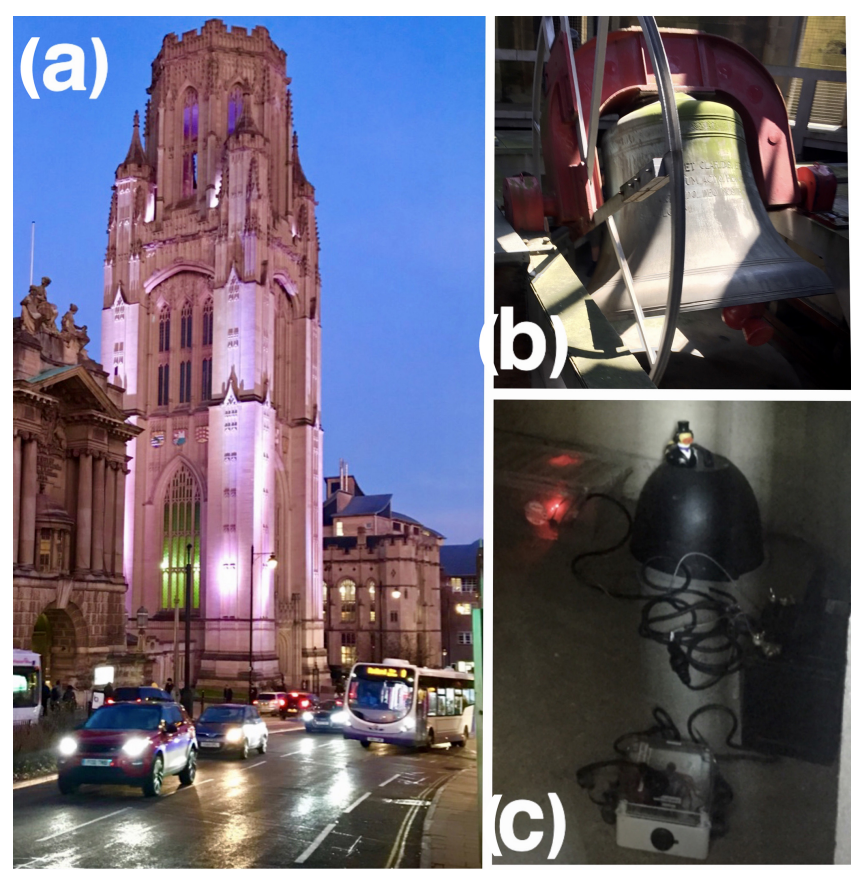

Figure 1. Great George bell (b) sits within the belfry of the Wills Memorial Building pictured in panel (a) on a typical weeknight. The broadband seismometer (c) installation set up in one of the alcoves above the bell. The instrument itself lies beneath the black dome with the Brunel rubber duck (geophysics group mascot) on top.

by the passage of buses on Park Street or that generated by seismic activity a thousand kilometres away, we reflected on technologies of recording, both those designed with a specific purpose in mind and those repurposed and used inventively and creatively. In its capacity to register vibrations, then, the bell's purpose as percussive instrument was revised, using the addition of a seismometer (Fig. 1), to become an instrument of measurement: a transformation that also asked us to think about how solid bodies, including our own, register the unpredictable motion of our unsettled planet. Bells have often been anthropomorphized, i.e. given human names and marked with inscriptions couched in the first person. If the place of Great George in the project lay partly in the rich potential of using a bell as an object to think with, its importance for us also owed something to the fact that it was physically present above us in the building in which we generally met and audible wherever we were in the city. Great George is an object that can be visited, touched and even swung; it is an object that is multi-vocal and expansive, in terms of both its E-flat tone - audible up to $20 \mathrm{~km}$ away - and its twitter feed - with a potentially global reach. The material qualities of the historic bell, cast in 1924, became particularly compelling when put into dialogue with modern scientific equipment, which was as exotic and mysterious to some of us as it was familiar to others.

\subsection{Thumbing through the Special Collections}

The project also involved encounters with objects that were more familiar to those of us working in the arts and humanities. A workshop in the Special Collections of the university library allowed us to look together at printed material on earthquakes ranging from the sixteenth to the nineteenth century, drawn mainly from the Eyles Collection (Eyles and Eyles, 1679-1983). Here, the objects of our attention were sometimes fragile books resting on foam cradles, with pages held down with snake weights, and works with evocative paragraph-long titles such as "A true and exact relation of the most dreadful earthquake which happened in the City of Naples and several parts of that Kingdom, June the 5th, 1688: whereby about forty cities and villages were either wholly ruin'd or extreamly damnified; eight thousand persons destroy'd and about eight hundred wounded; of which four hundred were digg'd out of the ruins, and many others miraculously preserved, translated from the Italian copy printed at Naples, by an eye-witness of those miserable ruins" (J. P., 1688). We scrutinized striking images such as Athanasius Kircher's cross sections of the Earth (Kircher, 2015), previously met as disembodied images on the web (a very different experience from turning the pages of Mundus Subterraneus, first printed in Latin in 1665, in its published book form). Voices from the past included descriptions of the sensations and emotions engendered by moving ground but also attempts to explain seismic activity, whether in terms of human wrongdoing and divine punishment or in terms of natural process. For the scientists amongst us, this brought home not only the differences in how science was conducted in previous centuries but also the resonances still perceptible with ideas held today. For those of us accustomed to the objects and setting of a rare-books collection, it was appreciable how the process of collaborative looking and reading differed from the sustained attention and focused questions of personal research. As we all circulated amongst the works, pointing out aspects and reading out passages - some of us more drawn to human testimony, others to scientific thinking - we provided contexts and explanations drawn from our own disciplinary frameworks.

\subsection{Public colloquium}

A single-day public colloquium allowed us to share some of our developing ideas with a wider audience and to benefit from the expertise and insights of others. Part of the day adopted a traditional format of short papers. Three invited speakers discussed projects that independently involved dialogue between disciplines and audiences. Stephen Vaughan, a photographer from Bath Spa University, spoke about his work on the impact of earthquakes in Japan and the United States. His focus on earthquake-induced tsunamis encouraged us to include water more fully in our thinking. By exploring how individual seismic events are discernible in the 
geological and dendrochronological record on both shores of the Pacific, he also gave us another way to think about distance and how seismic activity connects places. Paula Koelemeijer, an Earth scientist then at the University of Oxford, reported on research conducted with Beth Mortimer (Mortimer et al., 2018), a biological scientist at the University of Bristol, bringing animals into the conversation. Not only was this research team able to track the movement of the elephants, differentiate between them and determine the kind of ground they were traversing but they also hypothesized that the elephants themselves were possibly able to communicate in this way, picking up on different frequencies produced by the tread of fellow elephants across distances of tens to hundreds of kilometres. Paul Denton from the British Geological Survey spoke about crowd-generated earthquakes. Since the bulk of conversations about human-induced seismicity surrounds activities such as fracking, it was surprising for many to learn that amassed human footfall during outdoor rock concerts or football games could result in ground vibrations equivalent to those induced by a magnitude $2-3$ earthquake a few kilometres away. Low-cost seismometers, e.g. built from Lego and installed in schools, can pick up such vibrations as well as other earthquakes, extending the kinds of possible audience invited to attend to the movement of the unsettled planet.

Within the lecture theatre, charismatic objects from science and artistic practice helped to make ideas concrete. Speakers passed around 3D-printed models of the Earth and a fired-clay disc inscribed with a sound wave in the manner of an LP record. At the edge of the stage, a different kind of speaker - a huge amplifier - formed an intriguing presence, already reminding us of the sonic quality of seismic activity before allowing everyone to hear and feel the movement recorded by Great George the bell. Participants also gained a new awareness of the unsettled ground beneath the building by inhabiting other spaces, heading up the tower to meet Great George himself and look out over his soundscape, and sitting in a van at the base of the tower to listen to the amplified steps of passers-by (Fig. 2).

These activities were carried out concurrent with our seismic instrumentation of the bell tower. In the following sections, we describe the setup of our experiment as well as the data that we gathered from the instrument between March 2018 and January 2019. We describe the data gathered in the context of how our bell tower is positioned not only within the interactions of our city but also in a larger global picture.

\section{Data summary - monitoring the world from a bell tower}

To quantify the contemporary vibrations of our unsettled planet, we used two methods to collect seismic data. The bulk of these data were collected in and around the Wills Memorial Building (WMB). The WMB tower is a neo-Gothic re-

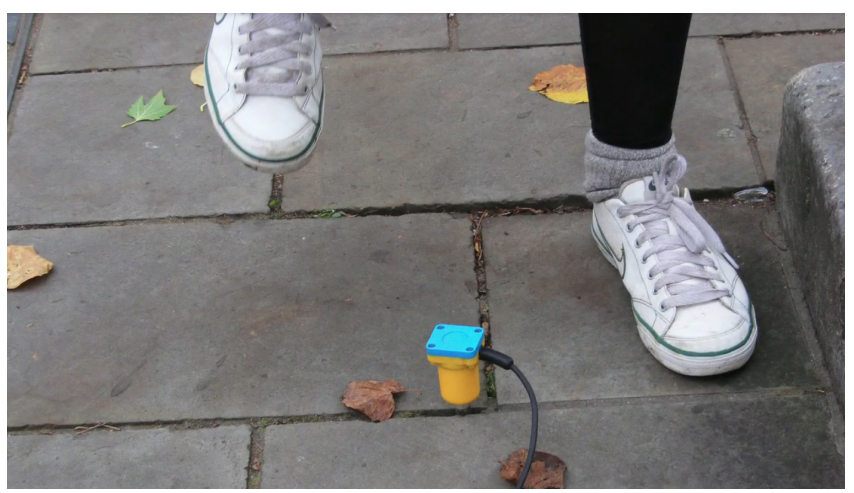

Figure 2. Workshop participant jumping near geophone set up to record foot traffic near the Wills Memorial Building.

inforced concrete structure which stands $65.5 \mathrm{~m}$ above the street level and is $16 \mathrm{~m}^{2}$ at its base. Topping the tower is an octagonal lantern which houses Great George. Great George is a large E-flat bell that measures $2 \mathrm{~m}$ tall by $2.5 \mathrm{~m}$ wide and weighs approximately $9.5 \mathrm{t}$ (Ringing For England, 2019; Towerbells.org, 2019), making it one of the largest bells in the UK. Great George rings hourly by the action of an external clapper, except on special occasions such as the university Charter Day when it is rung in the traditional way by experienced bell ringers using an internal clapper.

The first of the two data collection methods utilized a $10 \mathrm{~Hz}$ vertical geophone which was embedded in the shallow subsurface outside the WMB (Fig. 2). A geophone is a sensitive instrument that converts ground motion into an electrical signal via a magnet suspended within a coil on small springs. The data collected by the geophone, such as the footsteps of pedestrians on the pavement, were then converted into sound and played back through an audio system in real time. This allowed workshop participants to have both a visual and audio illustration of the vibrations recorded by the geophone.

The second method of data collection involved the installation of a Nanometrics Trillium 120 PA three-component broadband seismometer, connected to a Taurus data logger in the WMB tower (Fig. 1), to monitor the response of Great George not only to the activity in and around the building but also to signals from much farther distances. Such instruments are routinely deployed at seismic stations around the world and are used to monitor the Earth's seismic activity. This station was given the name GT01 and will be referred to as such in the figures that follow. A broadband seismometer allows for the accurate recording of seismic data (vibrations) in a broad range of frequencies, which is ideal for capturing the variety of signals reaching the tower. The three components of the seismometer record ground velocity in three orthogonal directions: east-west (HHE), north-south (HHN), and up-down or vertical (HHZ). The seismometer collected data at a rate of $100 \mathrm{~Hz}\left(100\right.$ samples s $\left.^{-1}\right)$, which effectively captures signals with frequencies up to $50 \mathrm{~Hz}$. At the low end, 
the instrument is sensitive to frequencies of less than $0.01 \mathrm{~Hz}$ or greater than $100 \mathrm{~s}$ in a period. These data were recorded intermittently between 23 March 2018 and January 2019 and several interesting signals have been extracted from the data, including the magnitude-4.2 Lincolnshire, UK, earthquake that occurred on 9 June 2018. The seismometer also recorded many distant - so-called teleseismic - earthquakes that occurred many thousands of kilometres away from the UK. In addition, several other noteworthy observations have been made. These include differences in signal recording between night and day and between weekday and weekend, variations in signal amplitude measured on the vertical and horizontal channels, and differences between the recordings made on the seismometer in the tower and other seismometers that were running on a lower floor of the Wills Memorial Building.

\subsection{Signals from the bell-ringing}

On most days, Great George rings hourly by the action of an external clapper striking the exterior of the bell. The sound produced by this ringing can be heard as far as $1.6 \mathrm{~km}$ (1 mile) away; the maximum distance at which the bell can be heard extends up to $20 \mathrm{~km}$ (12 miles) (Ringing For England, 2019) when the internal clapper is used on special occasions. The seismic signal produced by the ringing of the bell stands out from the background activity around the tower, because it is produced by a source that is near the tower seismometer. The signal also contains a distinctive set of frequencies, which gives the bell its recognizable sound.

There are a number of ways of visualizing seismic data; commonly, signals are displayed in the time domain where changes in amplitude of the waves are shown as a function of time (e.g. Fig. 3). Another method of visualizing seismic data is to display the signal in the frequency domain - here, the amount of energy in a frequency band is shown as a function of time. Such data are typically presented in a spectrogram as is done in Fig. 4, which represents the energy in each frequency band as a colour: warmer colours indicate stronger energy.

Figure 3 shows a day of data recordings on all three components of the seismometer. These recordings were made on 23 May 2018, the university Charter Day, when the bell was rung by a group of bell-ringers (see time-lapse video of the bell and Charter Day bell-ringing: https://vimeo.com/ 317784573, last access: 4 August 2020). The regular bell chimes are less than half the amplitude of the Charter Day bell-ringing which occurs at roughly 12:50 LT; the internal clapper produces a much louder sound than the external clapper. A zoomed-in view of one of the bell chimes (Fig. 4) shows that the individual chimes are visible in the data; there is also a low-amplitude signal, most visible before the first chime, created by the grinding motion of the external clapper leaving its housing to strike the bell.

\subsection{Variations in activity levels near the tower as a function of time}

In addition to the signals produced by the ringing bell, three noteworthy features are striking when looking at a full day of activity near the tower. First, the station is always recording activity - the area is never quiet. The tower sits along one of the major thoroughfares into and out of Bristol city centre, including an often-used route to and from the Bristol Royal Infirmary (hospital). Second, the data show a marked difference in activity near the tower during the day as opposed to the night-time. And third, there are several more hours of overnight activity on the weekends compared to a typical weeknight; this is somewhat different from the observations of Díaz et al. (2017), who note generally quieter weekends in their study. Figure 5 shows $2 \mathrm{~d}$ of activity, presented as $1 \mathrm{~h}$ of data in the time domain per line (much like an oldfashioned helicorder). The data for Thursday (14 June 2018 00:00 UTC to 15 June 2018 00:00 UTC) (Fig. 5a) show that there are fewer bursts of activity in the early morning hours than there are later in the day starting at about 05:00 UTC until $\sim 22: 00$ UTC. Figure 5 b shows activity recorded from 12:00 UTC on 16 June to 12:00 UTC on 17 June, which was a Saturday. There is more activity late into the Saturday night and early in the morning following Friday night.

Figure 6 displays the same data presented in Fig. 5 as a spectrogram. Again, both figures show higher amounts of energy or vibrations recorded during the daytime hours starting at about 06:00 LT and continuing throughout the day until about 22:00 LT at night on a typical weekday. They also show that this period of heightened activity extends almost $24 \mathrm{~h}$ on the weekend. This is particularly clear on the condensed seismogram displayed above the two spectrograms. These examples confirm what we already know, namely that there is more activity in a city centre during work hours and also late at night on the weekends; however, the recorded data also evidence the extent to which our cities are never silent, existing as environments continuously animated by ground vibrations. A notable departure from this constant hum of activity comes in the wake of the 2020 Covid-19-related lockdowns. The nearly global stay-at-home orders have resulted in a corresponding global decrease in seismic background noise levels. In Brussels, Belgium, for instance, the reduction in background noise is such that, in some cases, seismic events at the same high-frequency levels as the background noise can be detected and surface stations have the same signal quality as borehole stations buried at depths of $100 \mathrm{~m}$ (Gibney, 2020).

\subsection{Regional and teleseismic earthquakes}

During the $\sim 1$-year deployment of a seismic station in the WMB, several earthquakes were recorded from distant sources. Many of these occurred along plate boundaries, where tectonic plates collide, separate or slide past each other. Here we discuss an event from Indonesia, in which 


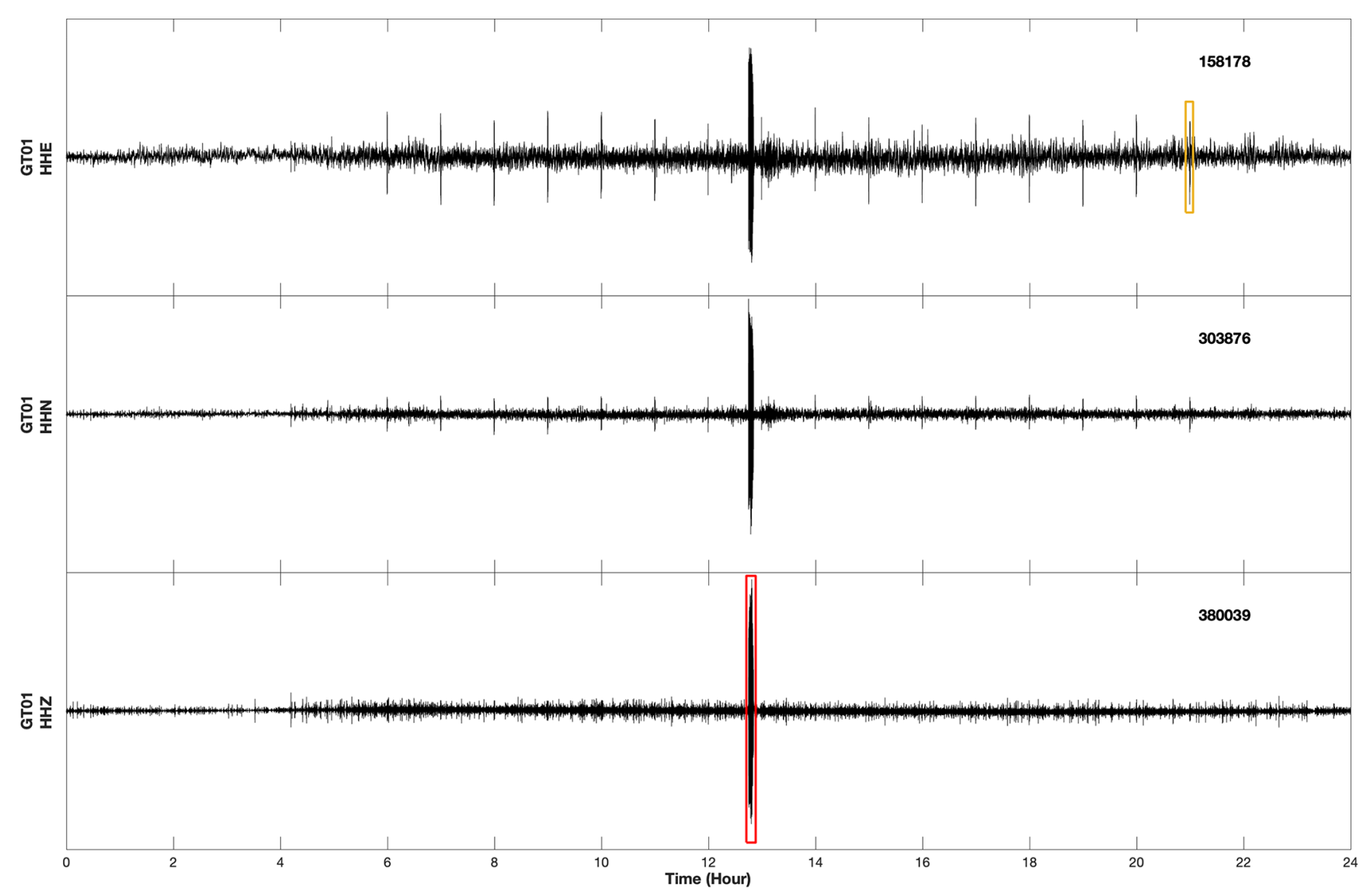

Figure 3. $24 \mathrm{~h}$ of continuous seismic data recorded on three channels (HHE, HHN, HHZ) at the seismic station GT01, which is housed in the bell tower of the Wills Memorial Building. The orange box on the HHE (top) trace highlights the bell chimes at 22:00 LT (21:00 UTC). The red box shows the much larger bell-ringing for the Charter Day commemoration on 23 May 2018. Both highlighted signals are explored further in Fig. 4. The numbers in the upper right corner of each trace indicate the absolute maximum amplitude of that trace in counts.

strike-slip faulting and the ensuing tsunami resulted in significant damage. We also show an event from Greece, where the plate boundary is more diffuse but still leads to large earthquakes. Finally, we consider events from Hawaii, recorded during an eruptive sequence of Killauea volcano. Here, the mantle is upwelling in a plume-like structure, forming the chain of Hawaiian islands. But first, we consider an earthquake much closer to home, which occurred on an ancient fault that is still settling down in response to the retreat of the large glacial sheets that once covered the British Isles. Cumulatively, these signals document the voice of a restless planet.

When an earthquake occurs, it releases energy in the form of seismic waves which radiate away from the earthquake source in all directions. This energy can be picked up by seismometers, because they are highly sensitive instruments capable of measuring vibrations not only in the immediate vicinity of the instrument but also from regional and teleseismic distances. What distinguishes a regional event from a teleseismic event is a bit arbitrary, but generally, teleseismic events are considered to be those that occur at distances greater than $1000 \mathrm{~km}$ and regional events are closer. Charles Richter (Richter, 1935) established an empirical magnitude scale for assessing the size of local seismic events (abbreviated $M_{1}$ ), which is defined as those closer than $500 \mathrm{~km}$ from a seismic station. There are several magnitude scales in use today, but Richter's local magnitude scale is among the most commonly used. When describing the size of larger seismic events (magnitude 4 and above), it is more common to use the moment magnitude scale (abbreviated $M_{\mathrm{w}}$ ), which is based on an assessment of the work (force times distance) done during earthquake rupture (Hanks and Kanamori, 1979). Where possible, seismologists prefer to use the $M_{\mathrm{w}}$ scale over the $M_{1}$ scale, as the former is directly related to physical processes (i.e. the slip on a fault area in rock of a given strength) (see, e.g. Kendall et al., 2019).

An example of a local or near-regional earthquake was recorded by the tower seismometer on 9 June 2018. This magnitude-4.3 earthquake occurred near Grimsby, Lincolnshire, UK. Signals from regional (or teleseismic) earthquakes look very different at distant stations than they do at stations near the source (compare the images in Fig. 7). 

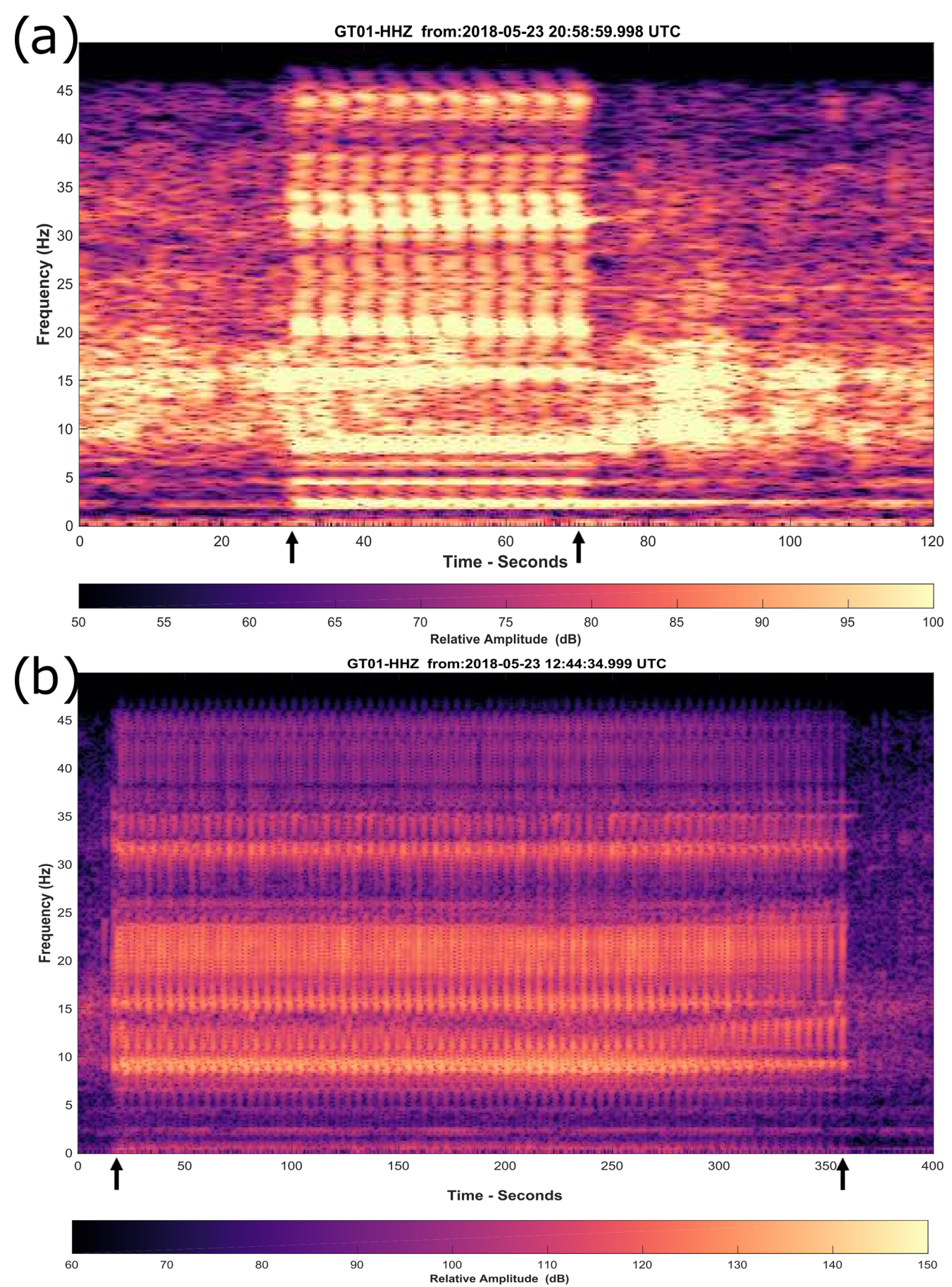

Figure 4. Zoomed-in spectrograms of the signals highlighted in Fig. 3. Panel (a) shows the 22:00 LT (21:00 UTC) chiming of Great George in which each peal is visible particularly in the $15-25 \mathrm{~Hz}$ range. Panel (b) shows a spectrogram of the Charter Day chimes; note that the timescales are different and the colour range on panel (b) is larger than in panel (a) to prevent colour saturation. Arrows indicate the start and end of the bell-ringing interval.

As a seismic wave propagates through the Earth, its signal gets weaker and weaker as the seismic wave spreads out this is known as spherical divergence or geometrical spreading. Furthermore, the Earth acts as a natural filter, absorbing high-frequency energy. The ability to distinguish these sig- nals from the background noise at distant stations often requires the application of a filter to remove cultural noise like that seen in Fig. 6 in the frequency range of 5-20 Hz. For most of the distant earthquakes recorded in the tower, a filter 
(a)

UB.GT01.HHZ:

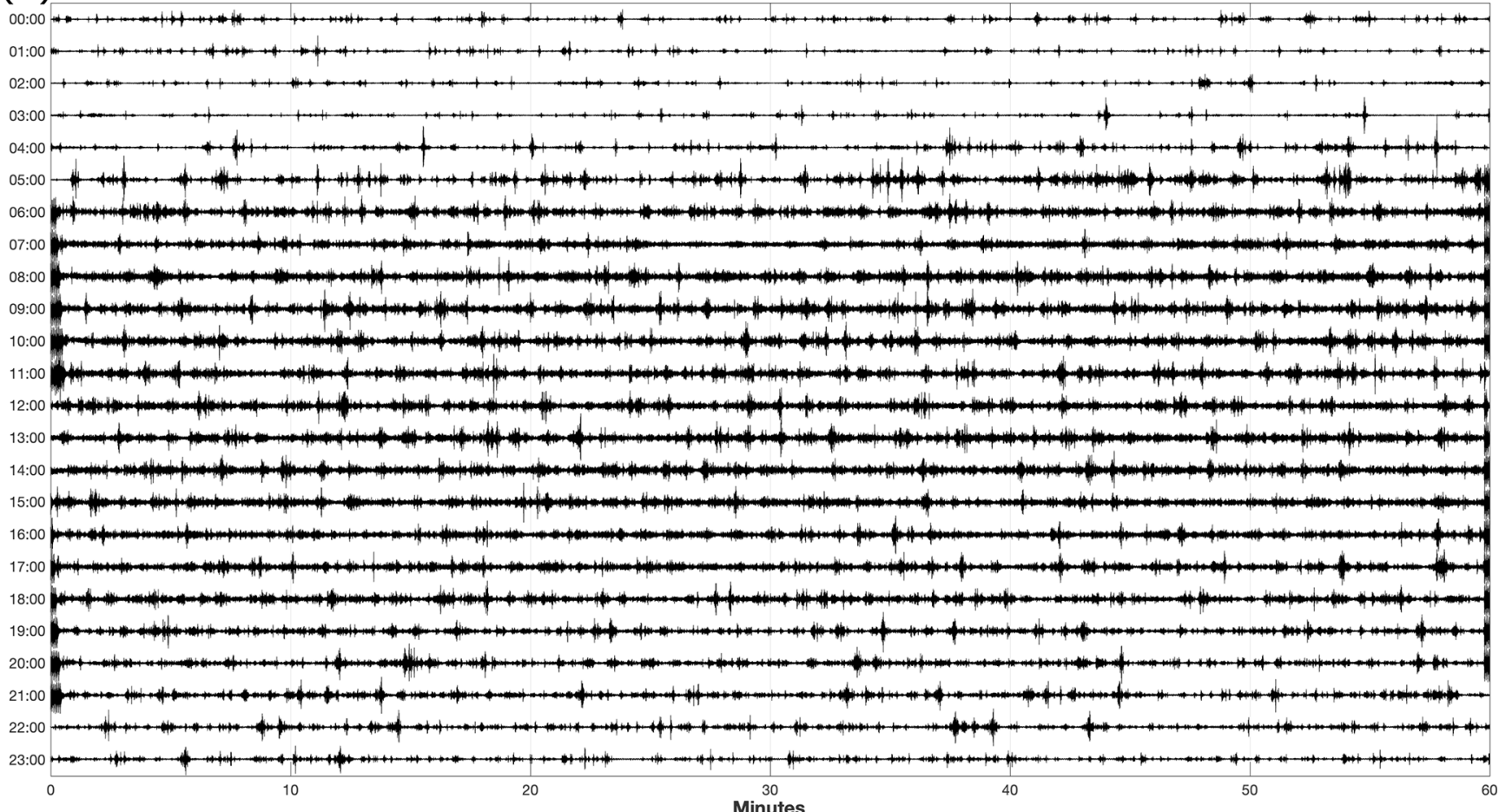

(b)

UB.GT01.HHZ:

2018-06-16 00:00:00 UTC to 2018-06-17 00:00:00 UTC

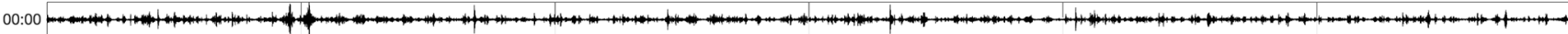

01:00 (1)

$2: 00$

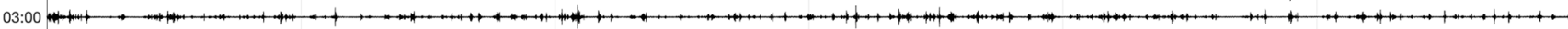

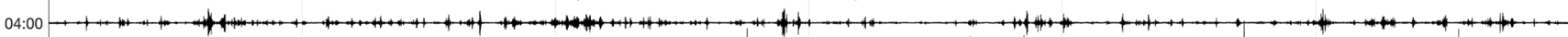

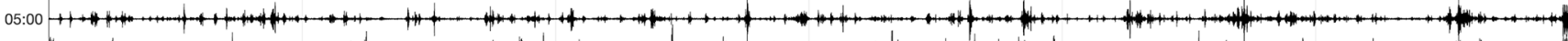

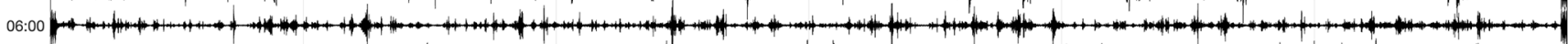

$07: 00$ +

08:00 (2)

09:00 -

10:00 -

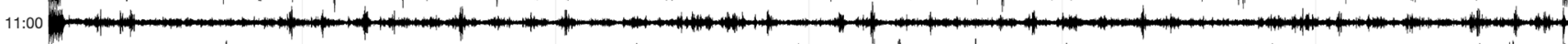

12:00 -

13:00 +

14:00

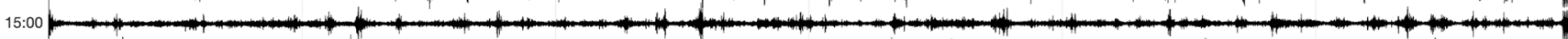

16:00 -

17:00 + 18:00 _ ב

19:00 +

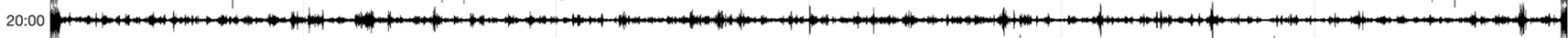
$21: 00$ W

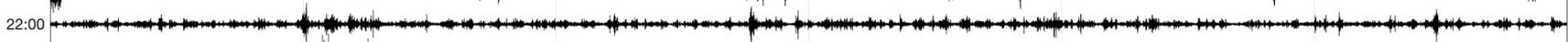

23:00 10

Figure 5. Helicorder recordings showing seismic signals (a) during a typical weekday near the WMB tower and (b) during a Saturday evening near the tower. During the week, while never fully quiet, activity tends to wane at night around 22:00 LT in contrast to a weekend night when activity is heightened until about 03:00 LT. 
(a)
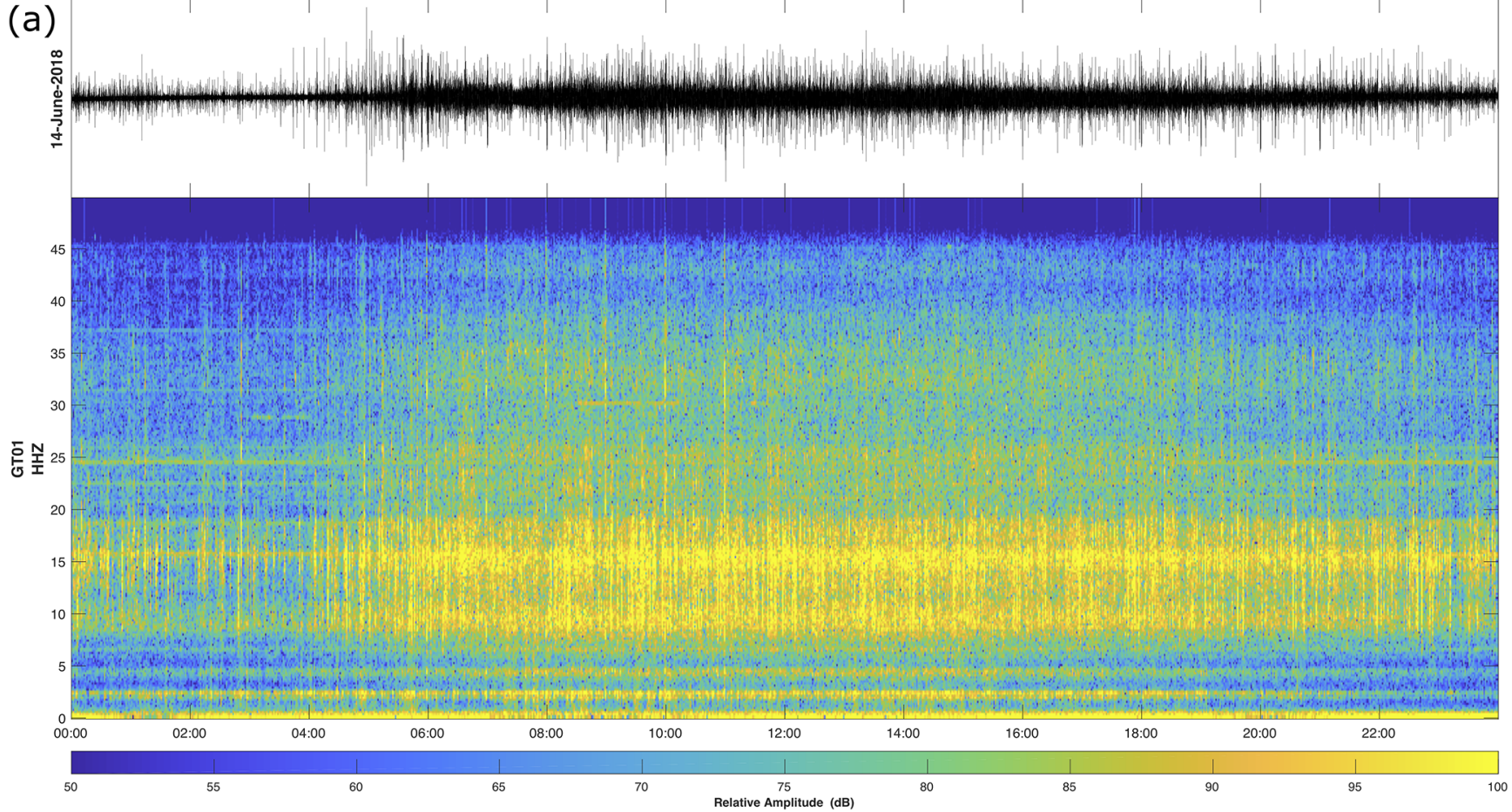

(b)
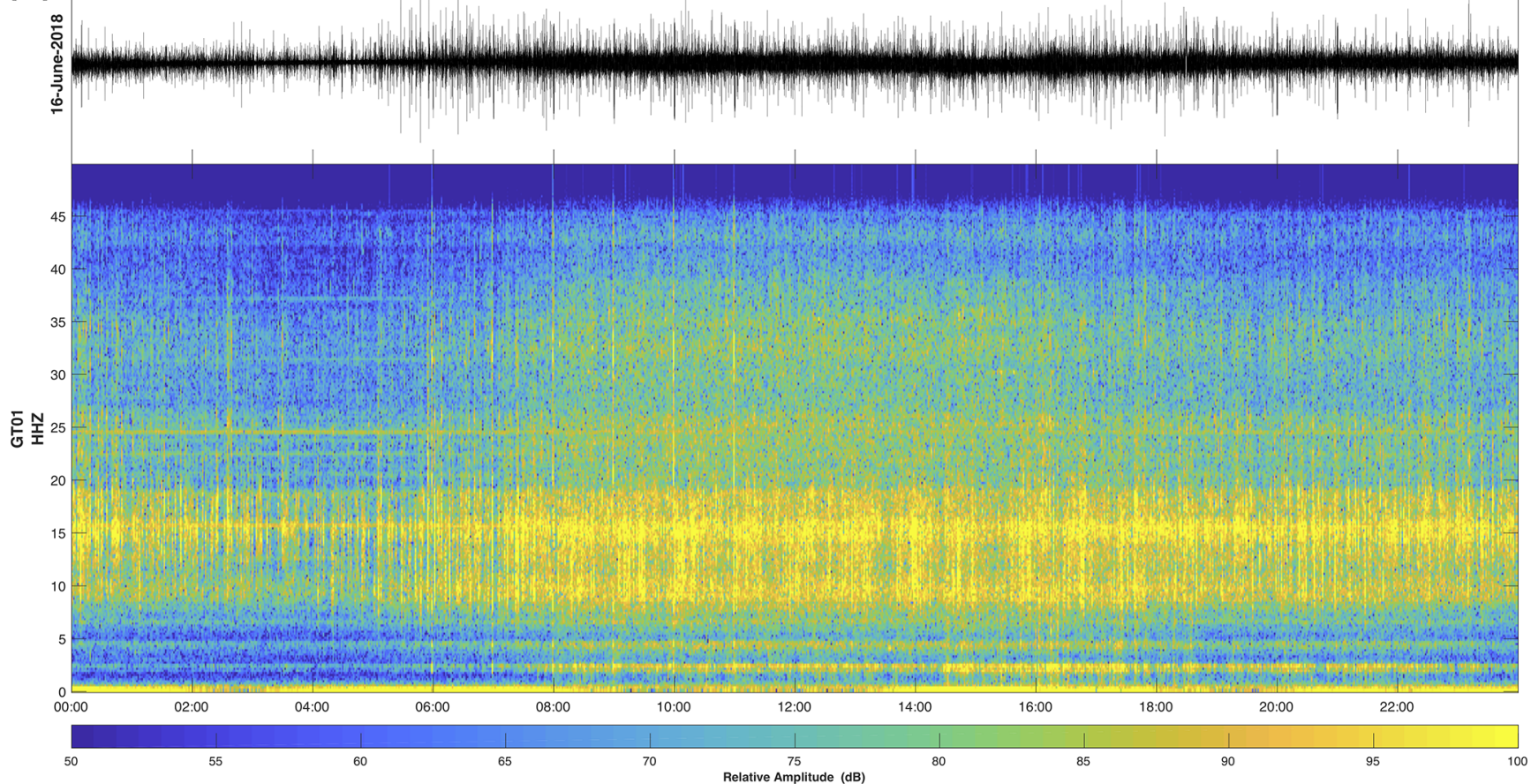

Figure 6. Spectrograms of the time-domain data shown in Fig. 5. The spectrogram is displayed in the bottom portion of panels: (a) a weekday and (b) a day on the weekend. The top portion of each panel condenses the $24 \mathrm{~h}$ of waveform data shown as a helicorder record in Fig. 5 into a single trace. The spectrograms show that there is strong energy in the $10-20 \mathrm{~Hz}$ frequency band throughout the day; this energy is almost continuous on the weekends (b) but wanes slightly overnight on a weekday (a). 

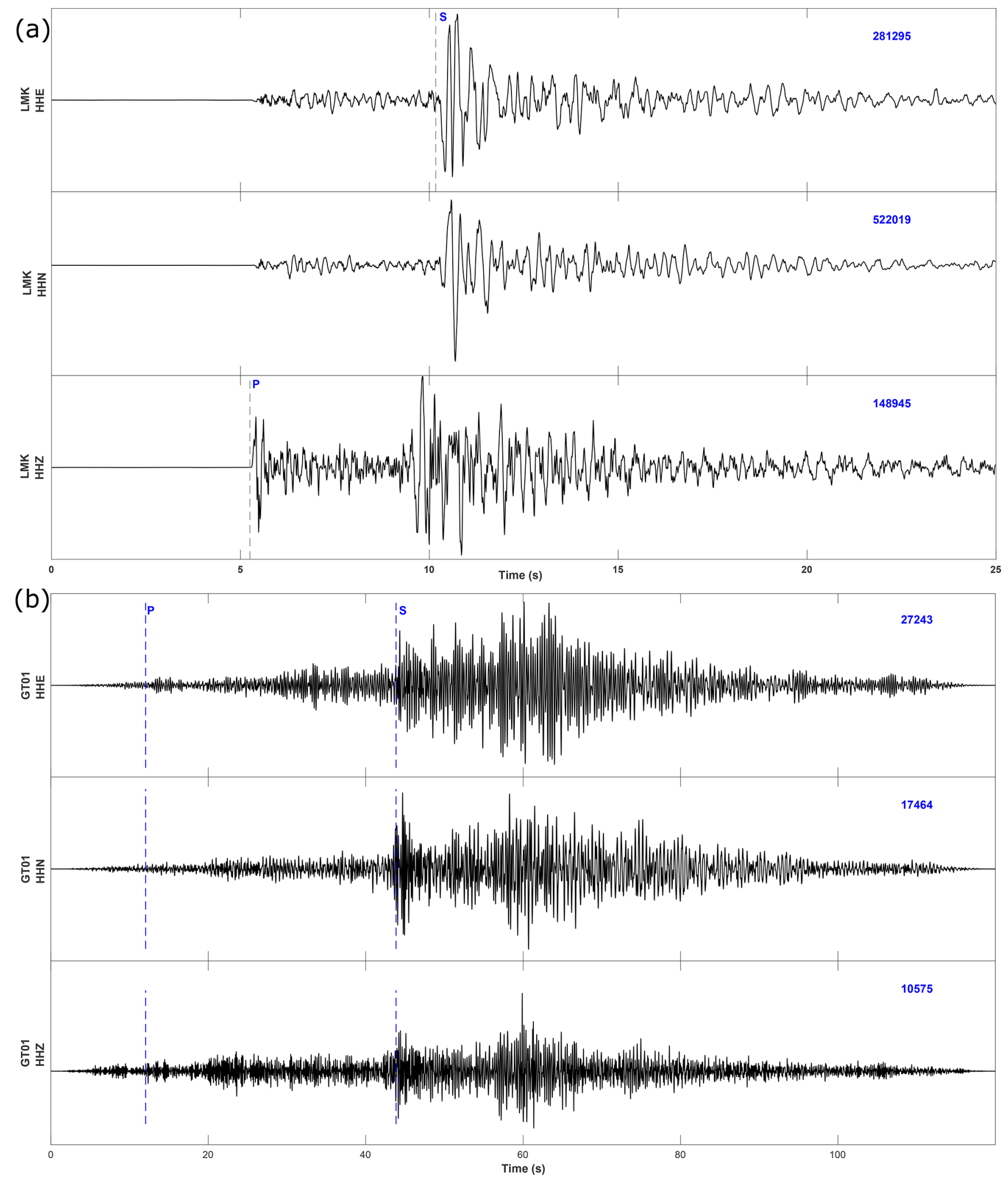

Figure 7. Lincolnshire earthquake (a) as recorded by station LMK ( $\sim 5 \mathrm{~km}$ from the source) and (b) the later arriving signal at station GT01 in the WMB tower $(\sim 300 \mathrm{~km}$ from the source). The HHZ traces show the vertical components of ground motion, and the HHE and HHN traces show the horizontal components, which are oriented $\mathrm{E}-\mathrm{W}$ and $\mathrm{N}-\mathrm{S}$, respectively. Note the difference between signal duration on both seismometers as well as the difference in peak amplitude given by the numbers in blue in the top right corner of each trace. The estimated arrivals of the $\mathrm{P}$ and $\mathrm{S}$ waves are indicated on both plots. Note that the zero time in each case is arbitrary and the timescale is different for the two seismometers. 
of 0.1 to $1 \mathrm{~Hz}$ was used, which is in a range well below the dominant cultural noise from traffic, people and machinery.

The seismic signal recorded near the Lincolnshire earthquake clearly shows the onset of the seismic wave train at station LMK, which is located near Market Rasen, Lincolnshire, England, UK (latitude $53.4573^{\circ} \mathrm{N}$, longitude $0.3274^{\circ} \mathrm{W}$ ), $\sim 5 \mathrm{~km}$ away from the earthquake epicentre. Seismic signals from an earthquake are comprised of many so-called phases. The clearest distinction to make is that between the first arriving $\mathrm{P}$ wave, which is a wave that propagates as a series of compressions and rarefactions, and the later arriving $\mathrm{S}$ wave, which propagates as oscillations transverse to the direction of wave propagation. The P-wave and S-wave arrivals are clearly visible at station LMK, with the $\mathrm{P}$ wave primarily visible on the vertical component of the seismometer (HHZ) and the $\mathrm{S}$ wave visible on the two horizontal components (HHE and HHN). In contrast, the signal from this earthquake recorded at GT01 in the WMB tower is much weaker in amplitude; the signal recorded at GT01 is about one-tenth the amplitude of that recorded at station LMK. Furthermore, the onset of the $\mathrm{P}$ wave and $\mathrm{S}$ wave is much less clear.

The Lincolnshire event was relatively small compared to several other large and devastating earthquakes that occurred in 2018. As indicated above, Richter's original magnitude scale is only appropriate for local events, so instead, these large events are reported in the moment magnitude $\left(M_{\mathrm{w}}\right)$ scale. One such event was the 28 September $2018 M_{\mathrm{w}} 7.5$ Palu, Indonesia, earthquake, which resulted in significant loss of life and property. It was the deadliest earthquake of 2018, and the earthquake and resulting tsunami and mudflows led to the estimated death of more than 4340 people, over 10000 injuries and the destruction of over 70000 homes (Goda et al., 2019).

Although this earthquake was almost $110^{\circ}$ (over $12000 \mathrm{~km}$ ) away from Bristol, the seismometer was able to detect the earthquake over $14 \mathrm{~min}$ after it occurred (Fig. 8). What was a national disaster and a source of human loss in a developing nation was only perceptible on sensitive seismic instruments in the UK. More poignantly, an equivalent sized earthquake in Japan would likely not lead to any loss of life. Whilst Japan and Indonesia experience large earthquakes every year, as they lie on the boundaries between tectonic plates, Japan has the money to engineer and construct earthquake-resilient buildings and infrastructure.

When examining data from distant, large earthquakes, early researchers (Oldham, 1906; Mohorovičić, 1910; Jeffreys, 1926; Lehmann, 1936) could identify simple arrivals from $\mathrm{P}$ and $\mathrm{S}$ waves, but they could also see other arrivals as seismic energy propagated and reverberated within the Earth. Some of these additional phases (Pdiff, SP, PKKP, etc.) can be seen in Figs. 8 and 9. The first signal to arrive at GT01 is the P wave (Pdiff) that transits the Earth's mantle and diffracts along the core-mantle boundary, which lies nearly $3000 \mathrm{~km}$ below our feet. Others that are visible include those that interact with the Earth's core - for example, PKKP, is the $\mathrm{P}$ wave that travels through the mantle and outer core, reflecting once off the underside of the core-mantle boundary before reaching the seismic station. Figure 9 shows the paths of various seismic phases that travelled from the site of the earthquake, denoted by the star at $0^{\circ}$ to the station in Bristol, over a quarter of the way around the planet. Here, we only show the phases that are most easily visible on the seismogram in Fig. 8, but it should be noted that there are other less-easily visible phases present in the seismic trace; there are many current research endeavours to study these more exotic signals. Teleseismic events such as this one provide our primary means of mapping the internal structure of the planet; they are how we know, for example, that the Earth has a core that is distinctly different from the mantle.

Seismic waves travel through the Earth like light travels through a prism; as the waves cross layers they encounter variations in material properties, which cause them to bend/refract, reflect or even change phase (e.g. P waves convert to $\mathrm{S}$ waves). Analysis of these changes in the seismic waves highlights the existence of the main layers within the Earth such as the solid inner core, the liquid outer core, the mantle and the comparatively thin crustal layer upon which life exists. The arrivals from an event such as the Palu earthquake, which occurred at a relatively shallow depth of $\sim 20 \mathrm{~km}$, illuminate the existence of the inner and outer cores when waves reflect off the inner core and either pass through or are diffracted off the outer core. Modern-day seismologists use arrivals from many earthquakes recorded by dense seismic networks to tomographically image the Earth's threedimensional internal structure, much the same way as medical imaging techniques are used to investigate the internal structure of the human body.

Closer to home, the $M_{\mathrm{w}} 6.8$ that occurred approximately $44 \mathrm{~km} \mathrm{SW}$ of Mouzaki, Greece, on 25 October 2018, had far fewer devastating consequences. Like the Palu event, this earthquake also registered on the tower seismometer and its signal is visible above the regular activity near the tower (see Fig. 10). Although smaller and less destructive than the Palu event, the Greece event occurred closer to Bristol and was therefore more apparent in the raw waveform data. Data from this earthquake also provide a treasure trove of information on the internal structure of the Earth. The P-wave and Swave arrivals are clearly visible phases that travel through the Earth's interior and are therefore referred to as body waves. The larger energy signal arriving after $1000 \mathrm{~s}$ is associated with surface waves that propagate along the surface of the Earth. Surface waves are always slower than body waves and are generally lower in dominant frequency.

\subsection{Variations in signal amplitude due to local site effects}

The amplitude of the seismic signal is a direct measure of the strength of vibrations affecting the seismometer. Signals that are produced by the horizontal motions of the ground or wind 


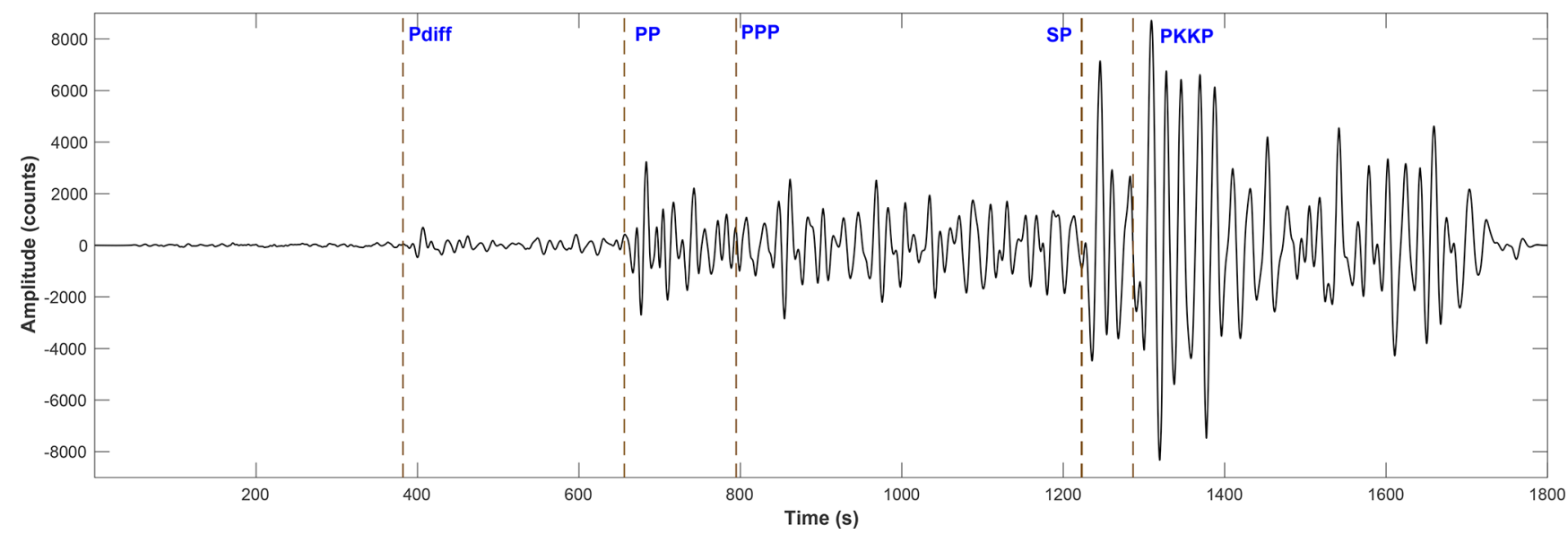

Figure 8. Filtered seismic waveform showing some of the seismic phases visible from the 28 September 2018 Palu, Indonesia, earthquake. The vertical-component waveform is bandpass filtered between 0.01 and $0.1 \mathrm{~Hz}$ to isolate the signals of interest. The earthquake occurred at a depth of $20 \mathrm{~km}$ and was $\sim 12200 \mathrm{~km}$ from the recording station (GT01) in the Wills Memorial Building (source USGS, 2018).

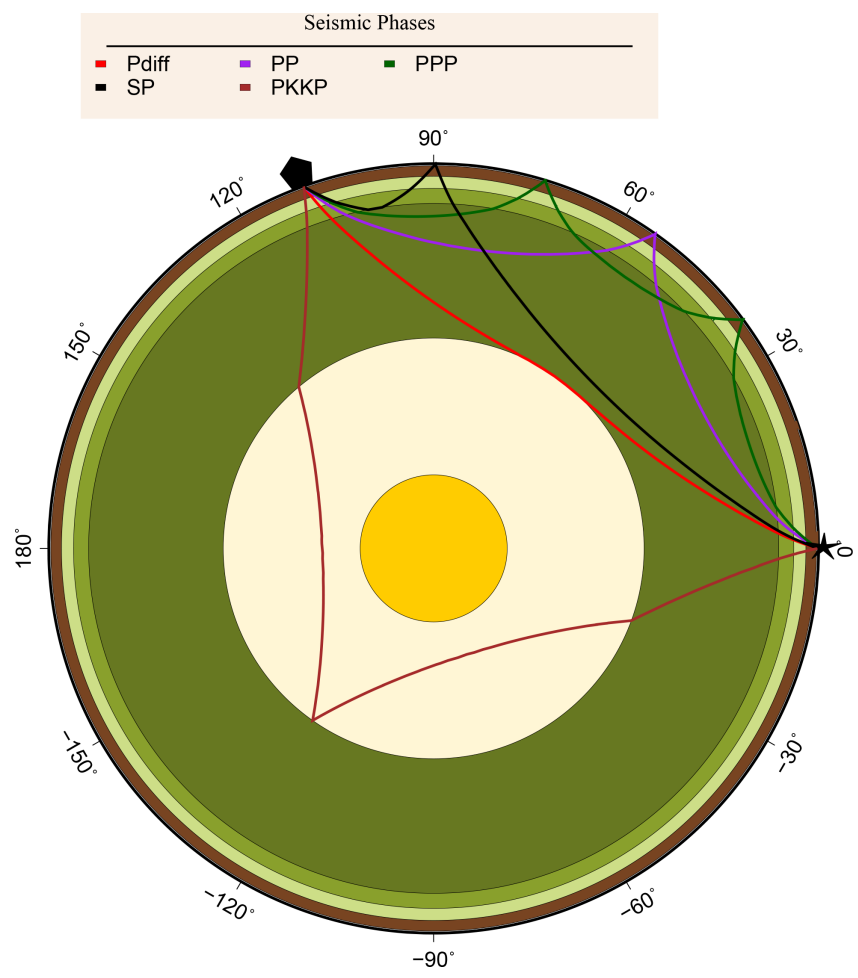

Figure 9. Plot showing some of the ray paths that seismic waves travelled on from the source in Indonesia to the seismic station set up in the WMB tower. The star shows the earthquake epicentre, while the pentagon denotes the station location. The inner core is shown in yellow, the outer core in beige, and the mantle in green and brown in the image. The thin crust on which we live is the black outer layer, which is barely visible in the image. The arrivals of these phases are marked on the seismogram in Fig. 8. should produce a stronger signal on the horizontal channels (HHE and HHN) than they would on the vertical channel (HHZ). Likewise, signals produced by the vertical movement of the ground beneath the tower should produce a stronger signal on the vertical channel than they do on the horizontal channels. A look at the data from the tower (Fig. 11) shows that many of the signals recorded have higher amplitude on the vertical channel than they do on the horizontal channels. This is somewhat surprising since the expectation prior to the launch of this experiment was that the natural sway of the building, coupled with the impact of strong winds, would have greater effect on the horizontal channels than it would the vertical.

At various points during the period that the seismometer was installed in the tower, there were other seismometers recording in the Wills Memorial Building. Comparison of the data from these seismometers to that recorded on the tower seismometer showed that the signal in the tower was being amplified on all channels. This is not surprising as shaking is expected to be amplified in tall buildings, particularly when they are impacted by low-frequency shaking that matches their resonant frequency. A building's resonant frequency is approximately inversely proportional to its height (Pratt et al., 2017). An example of this signal amplification is shown in Fig. 11; here, the traces are filtered between 2 and $10 \mathrm{~Hz}$ to separate the earthquake signal from the background noise. This figure shows a comparison between the signals recorded from the Lincolnshire earthquake discussed above as recorded by a seismic instrument on the first floor (one floor above the street level) and GT01 in the WMB tower. The amplitude of the data recorded in the tower is more than double that recorded on the lower level. 


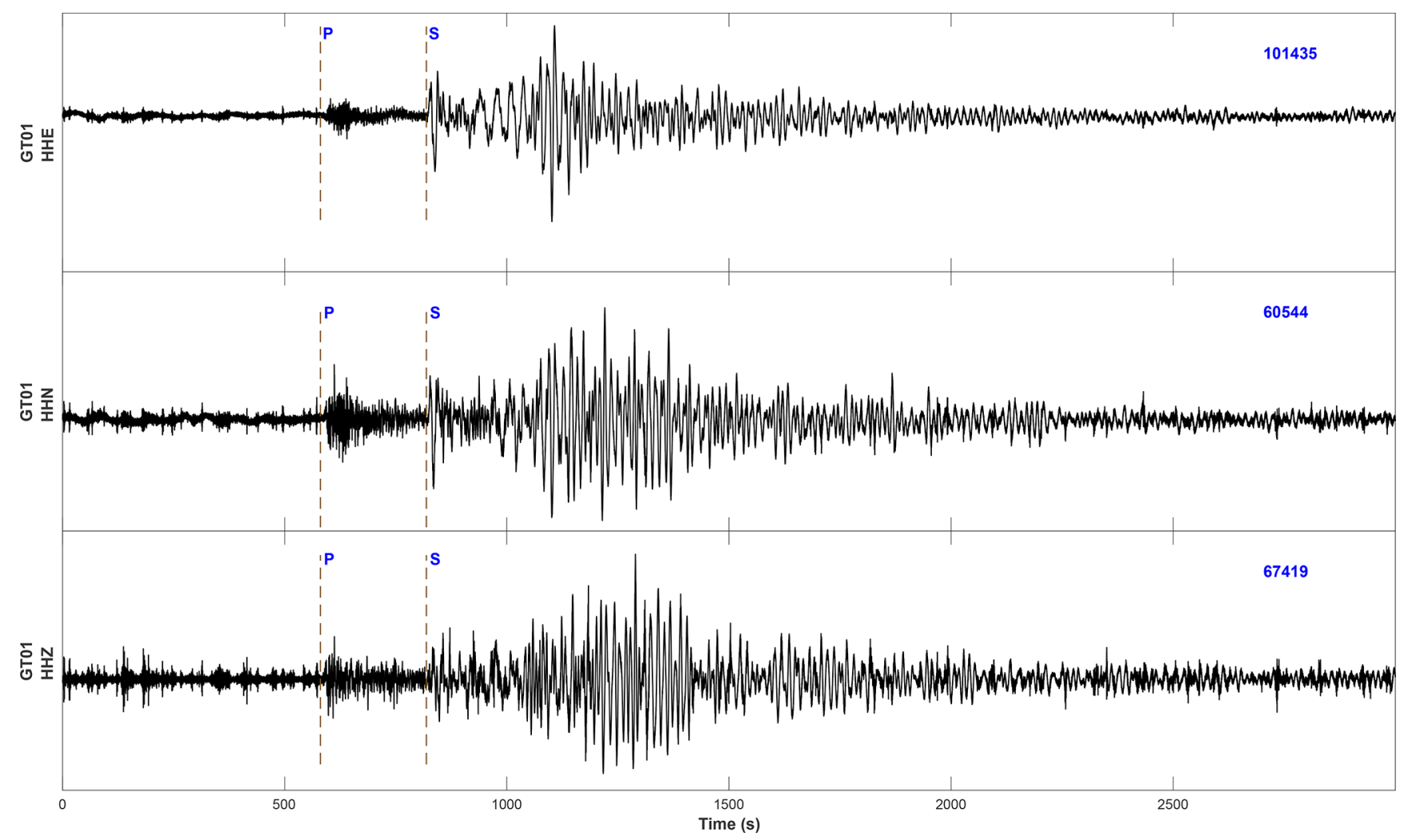

Figure 10. Seismic recording of the magnitude- 6.8 earthquake that occurred $44 \mathrm{~km} \mathrm{SW}$ of Mouzaki, Greece, on 25 October 2018 . The earthquake occurred at a depth of $14 \mathrm{~km}$ and was $\sim 2400 \mathrm{~km}$ from the recording station (GT01) in the Wills Memorial Building. The HHZ trace shows the vertical component of ground motion, and the HHE and HHN traces show the two horizontal components, which are oriented E-W and N-S, respectively. P-wave and S-wave arrivals are indicated; the stronger lower-frequency energy that arrives after $1000 \mathrm{~s}$ shows the arrival of the surface waves.

\subsection{How does it compare}

While the day-to-day "seismic" activity around the WMB seems quite vigorous, it goes largely unnoticed by the city's inhabitants. This raises questions of how Bristol's daily seismic activity compares to seismic signals from real earthquakes. Data recorded in the tower of both background noise and the bell peal were compared to seismic data from earthquakes of varying magnitudes recorded at stations in Hawaii. The Hawaiian earthquakes were recorded on seismic stations that were within 1 to $5 \mathrm{~km}$ from the earthquake epicentre. As illustrated in Fig. 12, the data from the tower are barely visible against the higher-amplitude signals produced by real earthquakes. The smallest real seismic event on these plots is a magnitude- 1 earthquake recorded at a station $1 \mathrm{~km}$ from the event. From the zoomed-in view in the inset of Fig. 12, the amplitude of the Bristol data (magenta and green) can be seen to fit neatly within the amplitude of the waveform for the magnitude- 1 event (blue waveform). The Bristol data sit well below the vibrational levels of both the magnitude3 (yellow) and the magnitude- 6 (red) events. Placed in this context, it is clear why the activity in the city may go largely unnoticed. The amount of shaking produced by a magnitude-
1 earthquake is seldom within the detection threshold of humans. However, as the event magnitude increases, it becomes easier for humans to detect a ground motion event in noisy settings even when the changes in magnitude are relatively small. This is because the commonly used earthquake magnitude scale is a measure of the amplitude of ground displacement and is logarithmic; this means that an increase of 1 in magnitude equates to a 10-fold increase in the amplitude of ground displacement. There is also a multi-fold increase between the energy released by an earthquake and its calculated magnitude. For instance, a magnitude- 3 earthquake releases roughly 32 times more seismic energy than does a magnitude-2 earthquake.

\subsection{Church bells ring during earthquakes}

Historical reports of earthquake activity frequently include notes on church bell peals accompanying ground shaking during an earthquake, even in situations where the bell is not proximal to the earthquake epicentre. Such incidents were reported in Charleston, SC, USA, following the 1811 New Madrid earthquake, which occurred on a fault approximately $977 \mathrm{~km}$ away from the church (LaCapra, 2011). Likewise, 


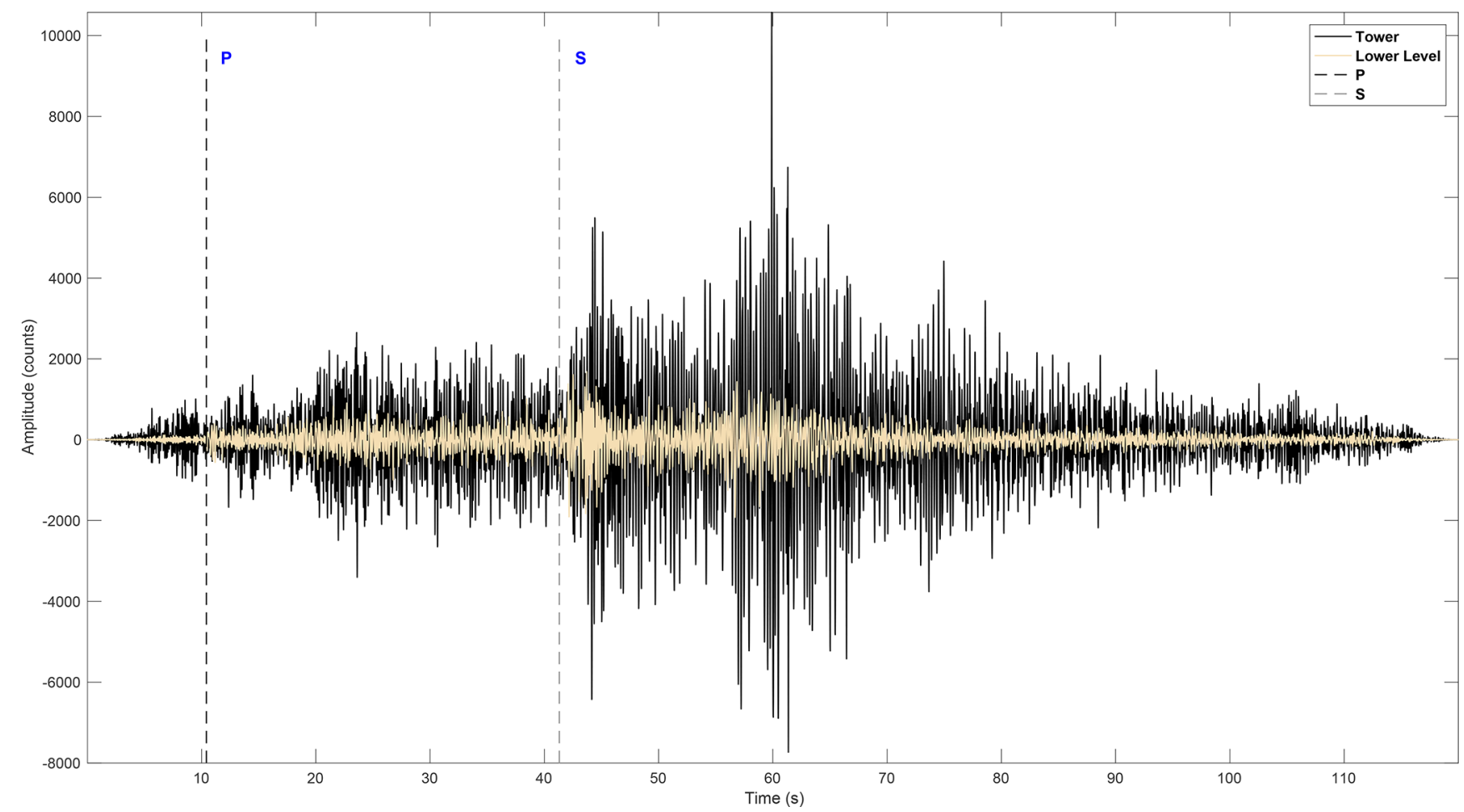

Figure 11. Seismic signals from the Lincolnshire earthquake recorded on one of the seismometers on the first floor of the WMB (beige) overprinted on a waveform of the same event recorded at station GT01 (black) in the WMB tower. The signal from the tower is more than double the amplitude of that recorded on the first floor of the building. Both traces were bandpass filtered between 2 and $10 \mathrm{~Hz}$.

the spontaneous ringing of church bells was heard as far away as Paris following the 1755 Lisbon, Portugal, earthquake (Penna and Rivers, 2013). Both earthquakes in the examples above were large, but it is also worth analysing the effect of the energy released on structures far away from the epicentres. The "modified Mercalli intensity scale" estimates that bells ring with earthquake intensities of V to VI, which roughly corresponds to the shaking experienced in a magnitude- 5 earthquake near the epicentre. The relation between earthquake magnitude and energy can be written as

$\log _{10} E=5.24+1.44 M$,

where $E$ is the energy released by the earthquake and $M$ is the moment magnitude of the earthquake magnitude (USGS Science Center, 2020). Therefore, a magnitude-5 event corresponds to an energy release of $2.75 \times 10^{12} \mathrm{~J}$.

This calculation shows that there is a large amount of energy released by a magnitude- 5 earthquake, but this number only relates to the energy released in the immediate environment of the fault that generated the earthquake. As the seismic energy propagates out from the earthquake epicentre, it dissipates; this is referred to as geometric spreading. The formulae for estimating the relationship between the energy dissipation and earthquake distance are given in Eqs. (2) and (3) for surface waves and body waves (P and S phase), respectively,
$E \propto \frac{E_{0}}{2 \pi r}$

$$
E \propto \frac{E_{0}}{2 \pi r^{2}}
$$

where, $r$ is the distance from the earthquake epicentre measured in metres and $E_{0}$ is the energy at the earthquake source. The surface waves occur later in the wave train than the body waves and tend to be of higher amplitude (see, for example, the Greek earthquake and the signals arriving after $1000 \mathrm{~s}$ in Fig. 10). These waves tend to cause the most shaking and therefore the most damage.

The 1811 New Madrid earthquake has an estimated magnitude range of 7.0-8.0 (Johnston, 1996; Hough, 2004; LaCapra, 2011). As an example, we can therefore estimate the amount of seismic energy that arrived in Charleston, SC, USA. The surface wave energy reaching the city was about 6 orders of magnitude larger than the body wave energy but was only equivalent to the energy released by a proximal magnitude-3 earthquake. Magnitude-3 earthquakes are considered weak events that cause little to no structural damage. Therefore, for ringing to occur under these conditions, other factors may have been influential. For instance, church bells are often left in the "ready" position (Woodhouse et al., 2012) in which the bell is placed just beyond its unstable equilib- 


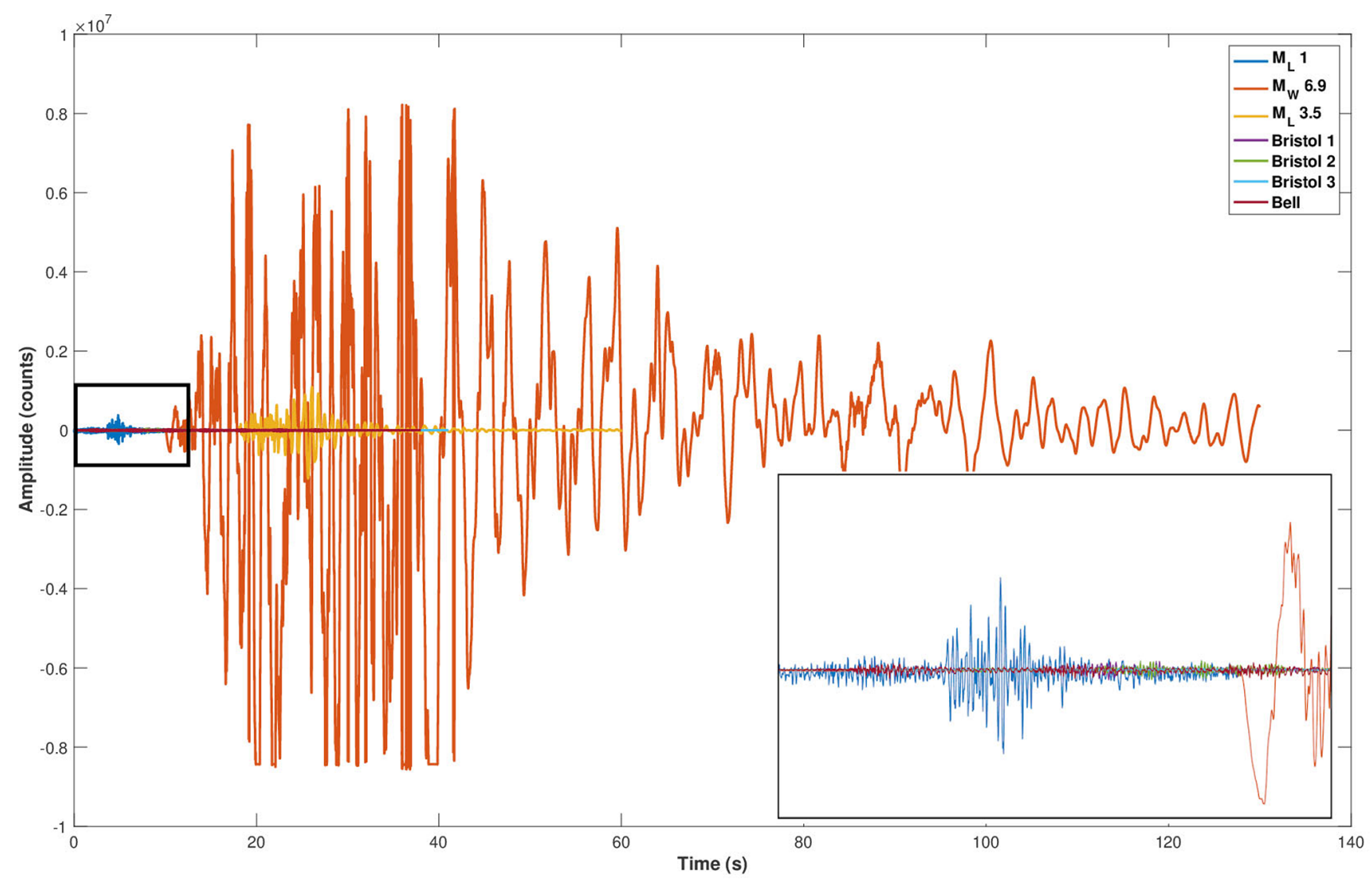

Figure 12. Comparison plot of different seismic signals from various sources recorded at stations in Hawaii (signals labelled $M_{1}$ and $M_{\mathrm{W}}$ ) and at GT01 in the WMB (signals labelled Bristol or Bell). Lower right inset shows a zoomed-in view of the same signals highlighted by the black rectangle in the main figure. From the inset image, it can be seen that the background noise and the bell-ringing (green and magenta signals, respectively) recorded in the WMB tower fits neatly into the signal of a local magnitude-1 event (dark blue) recorded at a station $1 \mathrm{~km}$ from the earthquake source in Hawaii. Given that magnitude-1 events are seldom felt, the inset makes it clear why the background activity around the tower goes largely unnoticed.

rium position and held in place by a sliding stopper. In the ready position, the inertial forces that must be overcome to swing the bell are greatly reduced, which in turn also reduces the amount of ground shaking necessary to move the bell. In cases where bells are rung by the action of an external clapper, it would likely be easier to move the external clapper during an earthquake than it would be to move the bell and its internal clapper.

A third factor that may have influenced the ringing of the church bells during an earthquake is the amplification effect of the bell tower. Research by Blakeborough (2001) showed that while the ringing of the bell is dependent on the mechanics of the bell and the tower in which it is hung, the peak ground acceleration (PGA) typically required for unplanned ringing needs to exceed the PGA of a magnitude- 5 earthquake. From our own experiment, illustrated in Fig. 11, there was at least an order of magnitude increase in amplification between the signals measured on the tower compared to the seismometer on the lower floors of the building. The signal measured in the tower was roughly double that measured on the lower floor but would not be enough to amplify the shaking from a magnitude- 3 to a magnitude- 5 event. Besides the basic amplification effects of the height of the tower, it is also reasonable to consider how resonance may play a role in the signal amplification. All structures have a natural frequency at which they will vibrate when a force is applied. For buildings, this natural frequency is affected by a number of factors such as building shape and material make-up but is most strongly affected by building height; tall buildings have a lower natural frequency than shorter ones. When incoming seismic waves have the same frequency as the natural frequency of a building, the shaking that that building experiences is amplified; this signal amplification may be up to 4-5 times as strong as the original arriving wave (Arnold et al., 2006). This resonance effect has been noted to cause differential building damage in past earthquakes; for example, during the 1985 Mexico City earthquake, the presence of soft sediments from an old lake bed beneath the city caused certain frequencies of the arriving earthquake wavefront to be amplified even though the city was $250 \mathrm{~km}$ away from 
the earthquake focus; the frequencies of these amplified signals coincided with the natural frequencies of buildings between 6 and 20 stories tall (Seed et al., 1988; Arnold et al., 2006). As such, the damage incurred by buildings in this height range was more severe than buildings outside of it. Therefore, if a similar resonance effect is experienced by a distant bell tower, it is possible that the tower may experience more shaking than other buildings in the area which could potentially result in unscheduled bell-ringing. All the above-mentioned factors may serve to increase the effect of seismic waves arriving from great distances; hence, a number of factors could have contributed to the historical unscheduled ringing of church bells reported following large earthquakes, such as that observed in Charleston following the New Madrid earthquake.

\subsection{Transforming seismic data into art}

Monitoring ground shaking and earthquake activity is mostly the job of scientists and researchers, whose areas of expertise connect with the distant global environment. And for those who live near an area that directly experiences the Earth's tectonic activities, the contact is only too real and impacts daily lives. But for many where this impact is not usually felt or experienced, being made aware of the constant noise and movement occurring under our feet can be surprising. The creative aspect of this project thus experimented with performance in order to encourage public engagement with the energy, force and distant origins of particular sources of sound; onlookers and audiences could fast track the "scientific explanations" of the unsettled Earth's activity and instead perceive it in a direct and visceral way. After hearing recordings captured during the $\sim 1$-year deployment of the seismic station in the WMB, for example, the choreographer Will Pegna was inspired to create a durational dance piece, All Terrain Training, performed in Peckham in an artist-led space. A photo captured during one of the acts of this performance is shown in Fig. 13. The particular source of the recordings in this case came from a $M_{\mathrm{W}} 7.4$ earthquake on 28 September 2018 near Sulawesi island, Indonesia, which is $\sim 12200 \mathrm{~km}$ from Bristol and a $M_{\mathrm{w}} 7.9$ on 6 September 2018, near Viti Levu island, Fiji, $\sim 16000 \mathrm{~km}$ away. These recordings were amplified and mixed live for the event by Shirley Pegna. To convey the power of the low, audible vibrating frequencies and the low, inaudible vibrating frequencies, the cone of a $56 \mathrm{~cm}$ (22-inch) subwoofer was employed along with speakers to create a surround-sound and immersive effect for the audience members (see subwoofer cone vibrating: https://vimeo.com/389225640, last access: 8 April 2020). A second performance piece was also made, inspired by the earthquake sounds mentioned above. This piece, Earth Din, presents these sounds via three subwoofers and four speakers placed in a large space where an audience can walk around amongst the speakers and be immersed in the sound and vibration. To create further interest by embellishing the

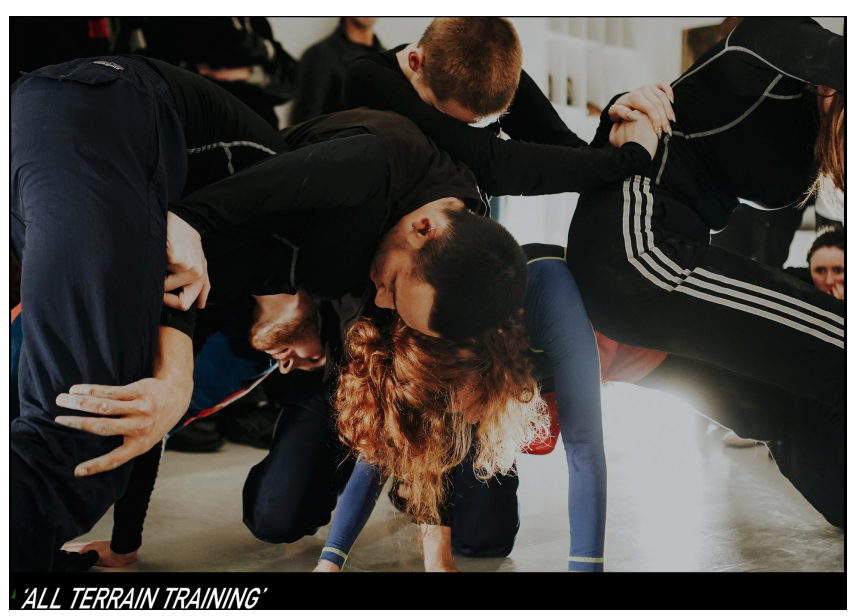

Figure 13. Artists perform a durational dance piece entitled All Terrain Training choreographed to sonified seismic data captured in the Wills Memorial Building tower that was amplified and live mixed during the event. The choreographed movements depict the collision, shearing and spreading of the tectonic plates that produced the earthquakes to which the piece was performed. Photo credit: Rocio Chacon.

experience of the natural sound, the piece also requires two musicians intermittently playing cello and double bass. The two musicians work with the sounds, reacting to them and each other in the moment, and improvising the sounds they add to the soundscape. The sharing of the sound and vibration from our planet to an audience via both these expressive performances thus creates another way to experience the Earth activity data recorded from the Wills Memorial Building tower.

We found that the set of vocabularies we have for size, scale, distance and time needed to be reimagined, processed and reassessed when contemplating the vastness of the Earth, particularly by those of us not used to thinking in this way. With this in mind, the third artwork coming from the ideas raised by this interdisciplinary project dealt with temporality, exploring the notion of geological time. The birth of planet Earth, its existence, and its projected demise spans a very different duration compared to our quotidian experience of the day to day. Shirley Pegna's The Rock Record, an object for a conceptual artwork, plays on the term used in geology to refer to the stratigraphic record that denotes how geologic time is captured in a rock sequence, and it is in this case a rock onto which is etched sound wave data from the recordings captured from the WMB. The seismic data recorded by the seismometer is first converted into a sound file, and in the same manner by which sound waves of music are etched into copper plate in the process of pressing a vinyl record, the etching we are currently creating will sit embedded in a record (LP) not made of vinyl but of very durable rock. Even this token design copy of a contemporary media player will outlast the 21st-century objects made of degradable vinyl, 


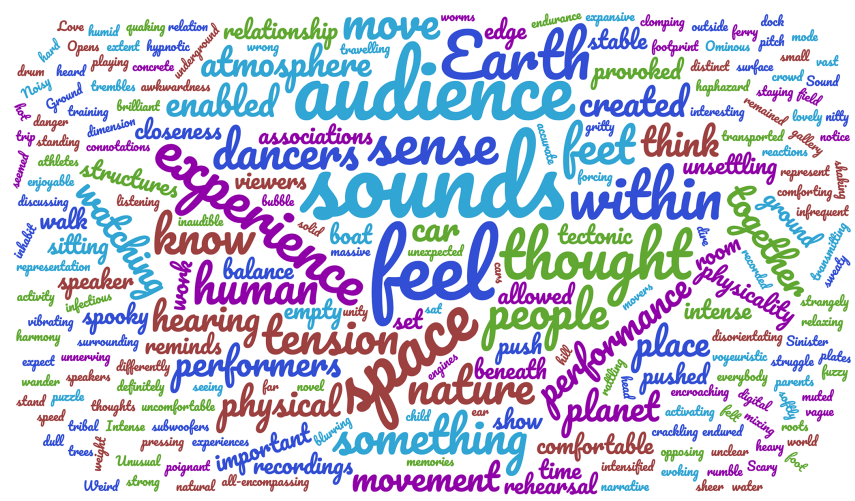

Figure 14. A word cloud formed by counting the occurrence of words in comments from participants, the audience, and performers in art performances and installations developed by Shirley Pegna, as part of the Unsettled Planet project. Performances include the All Terrain Training and the Earth Din projects. The installations are Ground Sound and You Are Here (see http://shirleypegna.com).

wood and plastic and possibly outlast even the span of human existence in rock form. In theory, it may even last into geological time itself.

The various art installations and performances that have resulted from this project demonstrate how people view everyday rumblings and vibrations of the ground beneath our feet, but they also give insights into how we view the more catastrophic nature of large earthquakes. Audience members were asked for feedback after the All Terrain Training (ATT) and Earth Din performances. We also gathered observations from people who experienced ground noise recorded by a geophone and amplified through a subwoofer (the Ground Sound and You Are Here projects - see http://shirleypegna. com, last access: 4 August 2020), as also demonstrated during our $1 \mathrm{~d}$ public workshop.

In general, the projects were well received and stimulated a diverse set of personal experiences. Nevertheless, there are some common threads through the remarks. To capture this, a summary of the comments from performers, participants and audience members is presented through a word cloud (Fig. 14). The most commonly occurring words are sounds, feel, audience, space and, Earth. As a first observation, the feedback shows how the art projects facilitate engagements with the wavelike nature of sound and ground motion; through touch and hearing we sense this interrelationship in the physics of wave propagation.

Another common theme concerns togetherness (or a shared human experience with planet Earth) and registers an ecological awareness that is simultaneously both connective and disquieting. As one of the dancers in the All Terrain Training performance observed: "The intense atmosphere that was created by the use of sound and movement together, as well as the awkwardness created by the closeness of the audience to the dancers, really struck me as being an accurate representation of the relationship between humans and the planet". Furthermore, an audience member noted that "ATT showed us how important it is for us to push against each other as people and find unity and harmony within that push. The work was moving and reminded us of how to remain human". Others who attended the Ground Sound installation said: "We leave a heavy footprint even though we don't mean to"; "I will walk more softly from now on". Both reflections are poignant reminders of our influence on the planet.

The feedback also demonstrates that how we react to ground motion is a very personal experience, and it can vary widely between individuals. Some found the performances comforting: "Love that sound"; "Very comforting", whilst others found them unsettling: "Spooky - scary"; "Made me feel ill". Some found the immediacy of the listening experience exciting: "Brilliant - noisy isn't it?", while for others it evoked memories of previous embodied experiences. Particularly striking is the use of simile - a figure of speech that looks for resemblance - in the responses to Ground Sound: "Like boat engines in the dock"; "Like under water"; "Like being a child again - car trip with your parents - being on the back seat".

The projects made people think about the unsettled nature of the Earth and question its cause ("Was it the trees and the roots (making the sound)?"). As an audience member at the All Terrain Training commented: "The field recordings were disorientating to the ear but seemed to balance perfectly against the dancers pressing together like tectonic plates". Interestingly, the performance also captured just how unsettling it can be to experience and earthquake, even within mediated terms as the comments of a dancer reveals: "allencompassing sound [...] gave dimension to the space, blurring our understanding of what was close and far away. The haphazard speed of the sounds left an unexpected nature to which you could not expect what was coming next".

Through these experiences, audience members and performers could derive a sense of uncertainty associated with experiencing an earthquake (how will I react? how bad will it get?). But their responses also demonstrate some of the challenges inherent in earthquake hazard awareness and preparedness. As one audience member said: "The voyeuristic nature of the performance would break once the performers pushed themselves into the crowd, activating the audience to move or become a part of the performance itself". In some ways, people are like this with natural disasters. What is initially an interesting or entertaining thing to watch quickly changes when you experience it first-hand and become part of it. This work shows how performance art can be used to better appreciate and communicate our connection with the Earth while also improving our awareness of natural hazards such as earthquakes. 


\section{What determines how people respond to ground shaking?}

As discussed above, the Earth is constantly moving and vibrating around us, although this motion is a frequently accepted part of our daily lives and often ignored. This general acceptance of ground motion leads to the question of what determines human responses to Earth vibrations. The eventual acceptance of the theory of plate tectonics, some 50 years ago, ushered in a new scientific paradigm that explains the driving forces behind earthquakes (McKenzie, 1977; Oreskes, 1999). The Earth through its frantic effort to cool itself through convection and conduction, has created and destroyed entire tectonic plates many times through its history. However, at various points throughout our human history, earthquakes have played a central role in human thought and development. From early ideas concerning punishment or exercise of divine wrath to the facilitation of dynastic changes to enable modernization, earthquakes have been explained through folklore, religion and philosophy (Winchilsea, 1669; Mallet, 1728; Ponton, 1872). The Great Lisbon earthquake of 1755 is a famous example of an earthquake accelerating divisions between religion and science, leading thinkers and poets to question the benevolence of a divine god. Indeed, as Juengel (2009) summarizes, "Lisbon has of course long loomed as the world historical event that cracked the foundation of Enlightenment optimism, driving Voltaire to abandon Leibniz, Pope, and the rightness of what is and to embrace Bayle's more profound doubt" (see also Nichols, 2014).

For historical earthquakes from the "pre-instrumental era" prior to the last decade of the nineteenth century, the only method of study is to use intensity, which is a number quantifying the degree of shaking at a particular point. In the case of the earthquake of 6 April 1580, for example, which was felt throughout a large portion of England, northern France and the Low Countries, and it is now thought to have had an epicentre in the Strait of Dover. A rich multi-lingual textual record of sources, including letters, new pamphlets, prayers, treatises and even satires, bears witness to the effects of the shock (Neilson et al., 1984). These sources include not only vivid literary responses to the earthquake, all the more fascinating for the different generic and ideological frameworks through which they are presented, but also document the particular effects felt in specific locations: from falling masonry to bells ringing and theatres shaking (Totaro, 2017). In his discussion of the event, the physician and translator Thomas Twyne (1580) wrote of how "the very shaking caused the bells in some steeples to knoll a stroke or twain", and that "the tops of half a dozen chimneys in London were cast down". As someone who did not feel the ground moving personally, he was keen to address how not everyone felt the effects of the earthquake equally:
Some that were above in their chambers, commonly judged that some violence had been done to their houses beneath. Some that remained below, found fault with tumbling and trampling above. Some imputed the rattling of wainscots to rats and weasels; the shaking of the beds, tables, and stools to dogs; and the quaking of their walls to their neighbours rushing on the other side. And as their opinions were sundry, so were their speeches thereupon diverse, until a common conference being had, they were resolved upon their common case and danger. For many not trusting to their own judgement, and partly also moved with fear, ran out into the streets to know if the like had happened unto others.

Twyne's contribution to the literary record of the 1580 earthquake is noteworthy owing to the way it captures the reactions of ordinary people and how they speculated about the causes of the ground shaking: looking first to everyday explanations for felt motion and then, having realized the novelty of the occurrence, to a kind of community consensus in order to understand more fully the scale and nature of what has happened. As Neilson et al. (1984) have shown, where multiple testimonies of this kind exist, details concerning felt effects at particular locations can be used to create intensity maps and to estimate the focal depth and magnitude of events, in this particular case resulting in an estimated Richter magnitude in the range $M_{1}$ 6.2-6.9.

From the perspectives of the humanities, then, responses to the ground moving can be seen to be determined by how lived experiences are processed and understood within preexisting cultural, theological, linguistic, philosophical and narrative frames. In historical reports it seems to matter whether the right language can be found to articulate the experience of the ground shaking, and this can often involve analogy in order to communicate the precise nature of the sensations experienced, which can then be likened to a cognate encounter of unsteadiness or vibration. Perhaps more importantly, the use of literary genre to construct a deliberate interpretative frame asks us to consider how genre gives shape to different kinds of temporal relationships and possible endings, owing to how genres can be used to determine narrative expectations by connecting causality, action and consequences in particular ways. In Europe, representations of earthquakes have been historically framed not only by tragic modes which speak of hubris, divine retribution, and even apocalypse, but also through providential models, including those of recuperation, where the earthquaking takes on the significance of a divine admonition: calling the faithful both to repent and to give thanks for their deliverance. These literary and theological frameworks co-exist in generative ways with local folklore, eyewitness testimony and the rationalizations of science, which in Europe, from the late sixteenth century onwards, grew out of the narrative methods 
of natural philosophy and drew on the authority of classical treatments of earthquakes and their causes by writers such as Aristotle and Lucretius (Prewitt, 1999; Passannante, 2008). In early modern Europe, ca. 1500-1800, surviving textual responses to natural disasters also reveal active transnational networks of printed news - an early version of our contemporary rapid mediation of such phenomena - and the ways in which environmental events, including floods, volcanoes and earthquakes, could be used for political ends, prompting the state-authorized publication of guides for public worship (Mears, 2012; Caracciolo, 2016). The historical records of natural disasters are also useful for dating literary works. The composition of William Shakespeare's Romeo and Juliet, for example, has traditionally been calculated on the basis of an earthquake reference made by the character of Juliet's Nurse (Thomas, 1949; Dodson, 1950).

To write in response to catastrophe, then, is to engage imaginatively with the limits of human reasoning and to formulate representational and aesthetic modes capable of handling epistemological change (Heringman, 2003). As Totaro (2017) observes of the 1580 event, "the earthquake imprinted the body-mind and altered all other sensory-related terrain immediately": a reaction that transformed the event into "a subject of epic proportion". To connect the scale of the earthquaking to the epic mode is perhaps to consider what it takes for a culture to live and rebuild in the aftermath of natural disaster; yet, for writers of the eighteenth century responding to the Lisbon earthquake of 1 November 1755, the magnitude of the destruction was connected to the sublime. As the New England Review notes (Voltaire and Fleming, 2005), summarizing the hitherto unparalleled scale of the initial event and subsequent cascade events, "within the space of five or six minutes, at least thirty thousand people died; the city was reduced to ruins, and the earthquake itself was accompanied by fire and the flooding of the Tagus River". The poem written by the French Enlightenment writer Voltaire (see Voltaire and Fleming, 2005) in response to the calamitous events responds to the mutable, tremulous nature of the Earth and includes the author's struggle with the long-held but now newly troubled idea that we live in the best of all possible worlds:

I can't conceive that "what is, ought to be,"

In this each doctor knows as much as me.

We're told by Plato, that man, in times of yore,

Wings gorgeous to his glorious body wore,

That all attacks he could unhurt sustain,

By death ne'er conquered, ne'er approached by pain.

Alas, how changed from such a brilliant state!

He crawls 'twixt heaven and earth, then yields to fate.

Look round this sublunary world, you'll find
That nature to destruction is consigned.

For Jörg Trempler (Trempler, 2013), the Lisbon earthquake not only ushered in a "new condition", owing to how the long-held "philosophical tendency that regarded the world as the best of all possible worlds" suddenly "found itself incapable of explaining away the destruction of a capital city", but also prompted the invention of "catastrophe" as an iconographical tradition. In the transient world figured by Voltaire it is the fate of contemporary humankind to walk or merely "crawl" upon the earth, rather than to be raised above it, and to be subject to the shaking, impermanent motions of a "sublunary" existence. The impact of the earthquake, as addressed in such terms, was to reveal the sublime power of nature's latent destructive capacity. Indeed, to narrate "catastrophe", as Juengel (2009) observes, is thus to confront the "telltale shuttling between measure and melancholy" that "structures the epistemological work of the postdisaster". As he explains, "the word catastrophe already possesses its own strophic or figural quality, for etymologically the term's Greek origins signal an 'overturning' of the order of things; thus 'catastrophe' becomes what we name a suffering heretofore unthinkable".

A similar scaling of response, used to confront the "unthinkable", is seen when comparing large earthquakes between regions in modern society. In general, people living in earthquake-prone areas in developed countries like Japan tend to be more comfortable with large earthquakes than those living in developing but earthquake-prone countries like Haiti. This relative comfort is imparted by confidence in the engineering and disaster management in place in developed countries (Kahn, 2005). However, this confidence can potentially be a double-edged sword leading to complacency which may result in significant loss of life and resources as illustrated in the aftermath of the 2011 Tohoku earthquake $\left(M_{\mathrm{w}}\right.$ 9.0-9.1). The ensuing tsunami led to the destruction of the Fukushima Daiichi nuclear power plant and a subsequent moratorium on nuclear energy in Japan amongst other regulatory changes. In the less developed country of Haiti, the $2010 M_{\mathrm{w}} 7$ earthquake affected over 2 million people, damaged $80 \%-90 \%$ of homes near the epicentre and had a death toll of well over 200000 people (DesRoches et al., 2011; Green and Miles, 2011). The impact of the earthquake in Haiti was likely due to two main causes: unlike Japan, Haiti's economy precludes the necessary level of engineering and disaster preparedness to minimize earthquake damage. Additionally, while a similar magnitude earthquake had struck the country in 1945, the memory of that prior event had most likely faded from the collective memory, leading to an underestimation of the disaster potential. We are left, then, with the idea, as Fountain and McLaughlin (2016) observe, that "there are no purely 'natural' disasters. Once a hazard phenomenon - flood, drought, tsunami, earthquake, typhoon/hurricane, geothermal activity or other catastrophe - intersects with human society, any purported naturalness 
dissolves. All disasters are enmeshed in human worlds involving economic, cultural, political and religious concerns".

In recent years, humans have also become acutely aware that their activities and interactions with the subsurface of the Earth induce earthquakes, which are sometimes in magnitude at dangerous levels. However, human acceptance of such induced seismicity is variable, depending on the contexts within which such activities occur, which are shaped by familiarity and economic goals. On one hand, the United Kingdom has experienced coal-mining-induced earthquakes since the Industrial Revolution and the start of large-scale underground mining (Redmayne, 1988; Wilson et al., 2015). On the other hand, much smaller induced earthquakes have paralysed the petroleum industry's efforts to produce domestic gas from shale formations in places such as Preese Hall near Blackpool in Lancashire. Ground motion associated with a stadium concert or sports events can be as large as that associated with subsurface activity (e.g. fracking), but the latter causes far greater alarm. Indeed, induced seismicity associated with fracking has proven to be very controversial, especially in the United Kingdom. During the fracking process, large volumes of high-pressure water are injected into deep rock formations that contain gas trapped in an impermeable matrix. The water stimulates a fracture network through the generation of tiny earthquakes - the energy produced by these small earthquakes is roughly equivalent to dropping a book (British Geological Survey, 2008). However, in rare cases, the water interacts with large pre-existing critically stressed faults. This water-fault interaction in turn leads to the generation of larger and felt seismicity. Such was the case in April 2011 when a $M_{\mathrm{w}} 2.3$ was triggered in Preese Hall, which led to an 18-month suspension of shale gas production in the United Kingdom (Clarke et al., 2014). It should be noted that this induced earthquake occurred at a depth of $3.6 \mathrm{~km}$ and would have only produced surficial ground motion of slightly higher amplitude than a train crossing a viaduct (see Horleston et al., 2013). When operations resumed in a nearby site (Preston New Road) in 2019, exploration was subject to a very strict traffic light system. Within this traffic light system, following a magnitude-0.5 earthquake, the operator is required to halt any further injection, reduce pressure in the system and monitor for any new seismicity before operations may potentially resume (Oil and Gas Authority, 2013). On the 26 August 2019, hydraulic fracture stimulation near the Preston New Road site in Lancashire triggered a $M_{1} 2.9$ earthquake, again leading to a moratorium on fracking in the UK (Kettlety et al., 2020).

In contrast, fracking has led to much larger earthquakes in Canada (up to $M 4.1$ in Fox Creek, Alberta; Schultz et al., 2017), but there is a far less restrictive traffic light system in place in Canada and perhaps lower public concern. The difference in reaction may be threefold: (a) Albertans are much more accustomed to the petroleum industry, as for many it is in fact their livelihood; (b) the region where shale gas activity is taking place in Canada is less populated than Lancashire; and (c) there is natural seismicity of similar magnitude in this part of Alberta, providing residents with a measure of familiarity with this level of ground shaking. The occurrence of large induced earthquakes is not solely associated with fracking. There are numerous anthropogenic causes of seismicity including mining, oil and gas activity, water impoundment via dams and weirs, and geothermal energy production (Foulger et al., 2018). While these activities normally lead to minor amounts of micro-seismicity (earthquakes less than $\left.M_{\mathrm{w}} 2.0\right)$, there are notable exceptions. For example, in 1967, the construction of the Koyna hydroelectric dam in India led to a $M_{\mathrm{w}} 6.6$ earthquake (Berg et al., 1969; Gupta et al., 1969). Oil and gas activity in Uzbekistan led to a $M_{\mathrm{w}} 7$ event in 1976 (Foulger et al., 2018). Recently, the American state of Oklahoma has seen a dramatic rise in seismicity, which is attributed to sub-surface wastewater injection associated with oil and gas extraction. Here, the largest events were greater than magnitude-5 and led to damage to several homes and businesses as well as a few injuries (Keranen et al., 2013).

\section{Closing thoughts}

During the final stages of writing this paper, Covid-19 reached the UK, and we all went into a period of extended lockdown and isolation. As everyone stayed at home, except those providing essential services, the anthropogenic noise in the country dropped to levels not experienced in decades. In addition to traditional journal sources (e.g. Gibney, 2020; Lecocq et al., 2020), seismologists across the world have been sharing on social media visual graphics that illustrate reductions in seismic noise across most seismic networks. Figure 15 is one such example, produced by Stephen Hicks at Imperial College London. It shows the seismic noise on two UK networks (British Geological Survey, BGS, and Raspberry Shake, RS), comparing levels before and after lockdown. It also shows a correlation with UK retail and recreational activity.

The British Geological Survey (BGS) operates a dense network of seismic stations, using instruments similar to those we deployed in the Wills Memorial Building. These stations are deliberately deployed in quiet settings. Nevertheless, a clear drop in background noise is visible starting in late March 2020 (Fig. 15). In recent years, seismometers have been deployed that cost a fraction of the price of conventional seismometers, but with only a slight degradation in instrument sensitivity. The Raspberry Shake instrument (http://raspberryshake.org, last access: 23 July 2020) is a very popular example. Unlike the more conventional seismometers, many of these instruments use a MEMS (microelectromechanical systems) sensor which fits on a small chip and thus reducing their size and cost relative to more traditional seismometers. Their use is a good example of citizen science in that the data are shared publicly so that scientists across the world can use the information recorded. They 

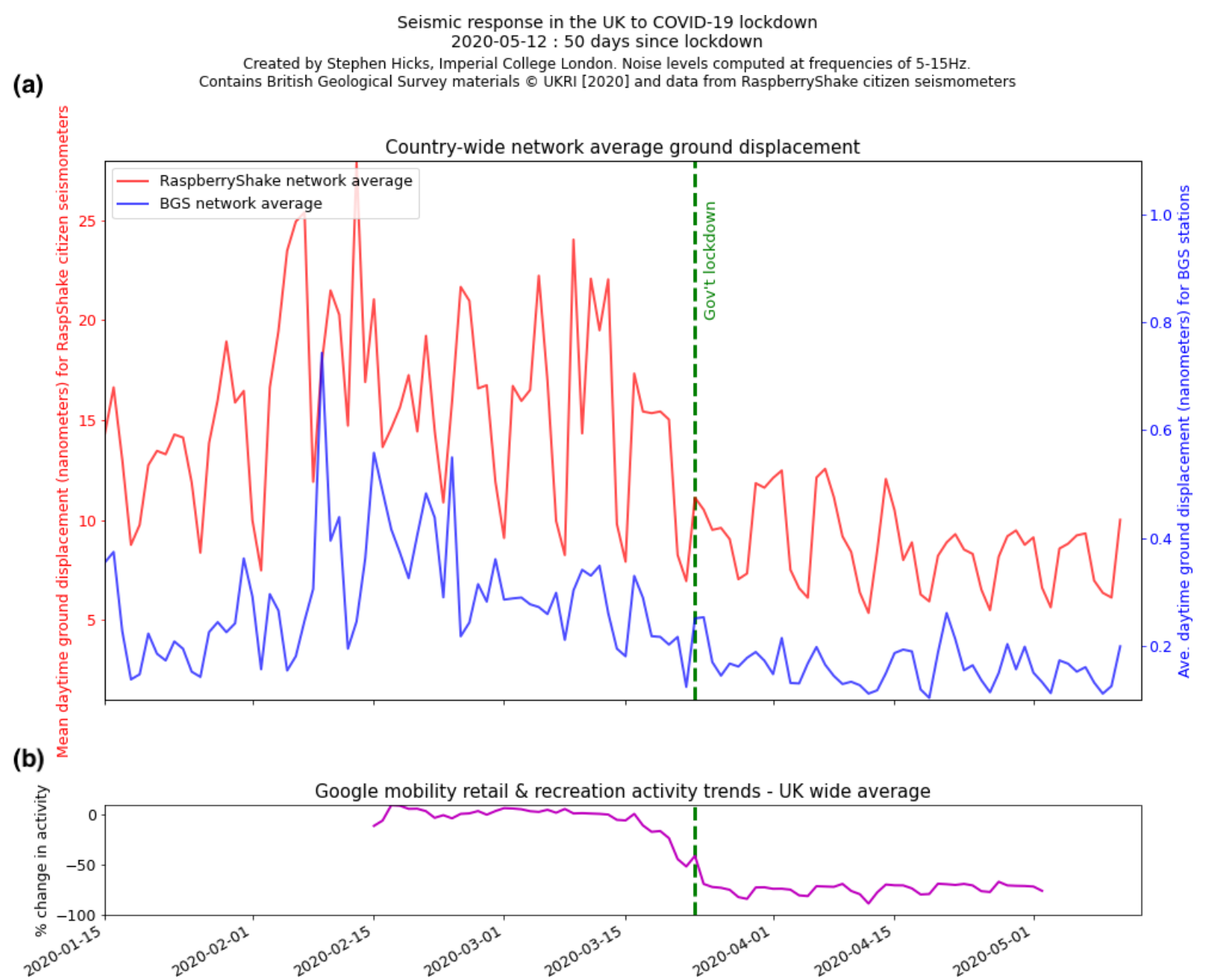

Figure 15. (a) Plot of average seismic noise recorded in the UK by the British Geological Survey (BGS) seismic network (blue) and the Raspberry Shake (RS) network (red) shows a marked decrease in seismic noise levels on both networks since the Covid-19 lockdown began on 23 March, 2020. This plot shows a decrease in average noise level of $\sim 0.6$ and $\sim 15 \mathrm{~nm}$ on the BGS and RS networks, respectively, between the peak noise levels in early February and the government lockdown in late March. (b) The Google mobility data also depict a similar decrease in activity in the UK associated with retail and recreation activity trends post-lockdown. This plot shows that UK recreation and retail activity dropped by $\sim 80 \%$ post-lockdown. Figure created by Stephen Hicks of Imperial College London.

are deployed in people's living rooms, sheds, etc. and there are currently more than 50 Raspberry Shake seismometers in operation in the UK (raspberryshake.net, 2020). The majority of the Raspberry Shake devices deployed in the UK are geophone-based sensors that have been electrically modified to give a response of $1-40 \mathrm{~Hz}$. Figure 15 shows how the seismic noise dropped on both networks, especially the Raspberry Shake network, during lockdown. There are also clear variations in noise between weekdays and weekends.

The ground beneath our feet may be unusually quiet, then, at this precise moment of writing; however, a glance at the language of recent headlines reveals that "seismic shifts" are occurring in other terms and in forms of activity across all areas of daily life: from consumer habits and corporate culture to educational practices and the trends of global politics. Indeed, our cross-disciplinary conversations prompted an increasing awareness of how we use different vocabularies, with different resonances, to articulate the phenomena of earthquakes and how these vocabularies resonate within everyday speech. From a literary perspective, it is striking how some of the most commonly used vocabularies carry metaphorical currency, having either been absorbed into colloquial ways of speaking of nonspecific adverse events or, more complexly, tasked with operating in intrinsically figurative ways themselves, retaining the memory of an emotional, moral, biological or physical charge: aftershock, stress-trigger, rift, fault, tremor, swarm, cascade and shadow zone. The increasingly over-used idiomatic term seismic shift, for example, used to connote conceptual change across all aspects of human experience, has 
been commonplace in our public discourse since the 1980s, as the Google Ngram Viewer (Lin et al., 2012) bears witness (see graph linked here: https://tinyurl.com/ydaob65o, last access: 10 April 2020). As Taylor and Dewsbury (2018) write, synthesizing the arguments of Metaphors We Live By by Lakoff and Johnson (2008) in their discussion of metaphor in science communication, "metaphors are not mere linguistic embellishments. Rather, they are foundations for thought processes and conceptual understanding that function to map meaning from one knowledge and/or perceptual domain to another". During this period of lockdown, we deploy the language of seismic activity - its shifts and its impacts - to give shape to something that we do not yet fully comprehend.

For the duration of the project, we also found ourselves drawn to a set of vocabularies related to the sonic potential of vibrations, whereby the earth can be thought to sound like a giant bell: harmonics, tones, fundamental modes and whispering gallery waves. Indeed, the bell like sonority of the Earth, our "blue planet", resembles a resonant chamber where seismic waves travel through and around its interior. The comparison is made with the Whispering Gallery in the roof of Saint Paul's Cathedral, where sound waves are reflected horizontally round the walls circle and bounce around multiple times because the angles involved are so slight (Fitzgerald, 2016). Interestingly, seismic phases can propagate around the inside of the planet in a similar fashion, clinging to the underside of the Earth's core-mantle boundary, some $3000 \mathrm{~km}$ beneath our feet. Our data from the Wills Memorial Building tower at the University of Bristol showed evidence of seismic waves coming not only from the tower bell, Great George, and local city impact but also extremely distant impacts travelling to the instrument from seismic activities on different continents. Our response to the data realized in sound and vibrations from the WMB tower seismometer could be described as hearing "music as audible physics" (Young, 1998), where the waves travelling around the inside of the Earth are described as resounding and reverberating. Reciprocally, such realizations can also be used to help scientists interpret seismic data (e.g. Paté et al., 2017). Transforming earthquake signals into audible sound helps us to better understand the scale of seismic shifts in the Earth (see, for example, http://www.seismicsoundlab.org, last access: 21 April 2020).

The technology, namely the seismometers and the geophone used either in (or within the vicinity of) the WMB tower to "listen in" to the ground, ultimately acted like bionic extensions to our human ears. Seismic waves reached the instruments from great distances by travelling through the ground, and so being able to hear and experience the waves altered our perception of what goes on under our feet and in our surroundings, by expanding the reach of our hearing and extending our auditory map further than the limitation of our anatomy: our planet might be unsettled but we are implicated in its motion in complex ways, with our own bodies forming part of a network of sensing instruments. The ear has been described as "half anatomy and half imagination" by writer and cultural critic Connor (2010), who describes how our perception of sound enhances our understanding when we can only imagine a sound's location but cannot see its source. Our technology also picked up different frequency waves, some audible and others inaudible to our ears, prompting a thought experiment to imagine what we could not hear with our human ears when perceiving seismic waves pitched below our auditory range. Yet, if we could not hear the waves as audible sound, they could still provide an impression of our surroundings. Musician Evelyn Glennie, who has a hearing impairment, comments in her Hearing Essay that "hearing is basically a specialized form of touch" (Glennie, 2015). When we could not hear but could only feel the vibration of waves, amplified through a speaker, we were still receiving an impression of the energy coming from the earth.

Connor (2010) describes sound and place as being intrinsically linked, where a "sound is the space in which it occurs" and "sonic essence inheres in spatial accident". In our discussions, we became fascinated by extending the notion that people "site" themselves in place by connecting to sound and to the idea that attending to vibrations in the Earth requires people not only to site themselves in relation to their local environment but also to their global environment. John Luther Adams, for example, in his work The Sonic Geography of Alaska, collates different elemental signals from the natural environment (Young, 1998). His reach is also global and he too states that "sound is a way of touching at a distance". From our own place of relative safety, then, we reevaluated our understanding of the ground beneath our feet and attended to what the vibrations travelling through it can tell us about the domains and limits of our situated disciplines and institutional habits. Our experiment to discern the motions of our unsettled planet, which focused on the bell Great George, thus ran alongside a second experiment, which tested novel collaborative structures of research and aesthetic practice. The result has been an unsettling of accustomed methods, stress-testing the disciplinary foundations on which we build.

Data availability. The raw data utilized in this study have been archived with the National Geoscience Data Centre (NGDC; https://doi.org/10.5285/0f7e4448-ac5f-478d-83b4-408edc244f3b, George, 2020).

Author contributions. With the exception of the data analysis section that was largely written by JMK and OAG, all co-authors contributed equally to the remaining sections of the article. This was done as part of a writing retreat; each of the co-authors wrote a page or more for each of the sections of the paper which was later synthesized to the final version presented in the article. 
Competing interests. The authors declare that they have no conflict of interest.

Acknowledgements. This work was funded and facilitated by the University of Bristol's Brigstow Institute as part of their "Living well with uncertainty" initiative in 2018. Ophelia Ann George and John Michael Kendall were funded by NERC grant NE/R018006/1. We gratefully acknowledge support from the sponsors of the Bristol University Microseismicity Projects (BUMPS). We thank Stephen Hicks for generating the plot in Fig. 15. We are also grateful to Michael Richardson, who facilitated our access to the Special Collections of the University of Bristol's library and to its holdings in our area of interest. We would also like to express gratitude to reviewers Paul Denton and Susanne Maciel for their thorough reviews which helped to make the article stronger.

Financial support. This research has been supported by the University of Bristol's Brigstow Institute ("Living well with uncertainty" initiative) and NERC (grant no. NE/R018006/1).

Review statement. This paper was edited by Mirjam Sophia Glessmer and reviewed by Paul Denton and Susanne Maciel.

\section{References}

Arnold, C., Bolt, B., Dreger, D., Elsesser, E., Eisner, R., Holmes, W., McGavin, G., and Theodoropoulos, C.: Designing for earthquakes: A manual for architects, Risk Management Series, Mimari Tasarımda Deprem, FEMA, Washington D.C., USA, 2006.

Bennett, J.: Vibrant matter: A political ecology of things, Duke University Press, Durham, North Carolina, USA, 2010.

Berg, G., Das, Y., Gokhale, K., and Setlur, A.: The Koyna, India, Earthquakes, Proc. 4th World Conference on Earthquake Engineering, 13-18 January 1969, Santiago de Chile, Chile, 44-57, 1969.

Blakeborough, A.: An analytical response of church bells to earthquake excitation, J. Earthq. Eng., 5, 69-92, 2001.

British Geological Survey: How are earthquakes dectected, available at: https://www.bgs.ac.uk/discovering-geology/ earth-hazards/earthquakes/how-are-earthquakes-detected, last access: 30 October 2020.

Caracciolo, C. H.: Natural Disasters and the European Printed News Network, in: News networks in early modern Europe, Brill, the Netherlands, 756-778, 2016.

Clarke, H., Eisner, L., Styles, P., and Turner, P.: Felt seismicity associated with shale gas hydraulic fracturing: The first documented example in Europe, Geophys. Res. Lett., 41, 8308-8314, 2014.

Connor, S.: Secession, Sonic Acts XIII: The Poetics of Space, 27 February 2010, Amsterdam, the Netherlands, 2010.

DesRoches, R., Comerio, M., Eberhard, M., Mooney, W., and Rix, G. J.: Overview of the 2010 Haiti earthquake, Earthq. Spectra, $27,1-21,2011$
Díaz, J., Ruiz, M., Sánchez-Pastor, P. S., and Romero, P.: Urban seismology: On the origin of earth vibrations within a city, Sci. Rep., 7, 1-11, 2017.

Dodson, S.: Notes on the Earthquake, Mod. Lang. Notes, 65, p. 144, 1950.

Eyles, V. and Eyles, J.: Eyles Collection, GB 3 DM 1186, University of Bristol Special Collections, Bristol, UK, 1679-1983.

Fitzgerald, J.: How does the Whispering Gallery at St Paul's actually work?, available at: https://ondonist.com/2016/05/ how-does-the-whispering-gallery-at-st-paul-s-actually-work (last access: 6 August 2019), 2016.

Foulger, G. R., Wilson, M. P., Gluyas, J. G., Julian, B. R., and Davies, R. J.: Global review of humaninduced earthquakes, Earth-Sci. Rev., 178, 438-514, https://doi.org/10.1016/j.earscirev.2017.07.008, 2018.

Fountain, P. and McLaughlin, L.: Salvage and salvation: guest editors' introduction, Asian Ethnol., 75, 1-28, 2016.

George, O.: Seismic Data Archive for the Unsettled Earth Project, Bristol, England, UK, British Geological Survey, Dataset, https://doi.org/10.5285/0f7e4448-ac5f-478d-83b4408edc244f3b, 2020.

Gibney, E.: Coronavirus lockdowns have changed the way Earth moves, Nature, 580, 176-177, 2020.

Glennie, E.: Evelyn Glennie Sounds-Off, available at: https://www. evelyn.co.uk/hearing-essay (last access: 6 August 2019), 2015.

Goda, K., Mori, N., Yasuda, T., Prasetyo, A., Muhammad, A., and Tsujio, D.: Cascading Geological Hazards and Risks of the 2018 Sulawesi Indonesia Earthquake and Sensitivity Analysis of Tsunami Inundation Simulations, Front. Earth Sci., 7, 1-16, https://doi.org/10.3389/feart.2019.00261, 2019.

Green, R. and Miles, S.: Social Impacts of the 12 January 2010 Haiti Earthquake, Earthq. Spectra, 27, S447-S462, https://doi.org/10.1193/1.3637746, 2011.

Gupta, H., Narain, H., Rastogi, B., and Mohan, I.: A study of the Koyna earthquake of December 10, 1967, B. Seismol. Soc. Am. 59, 1149-1162, 1969.

Hanks, T. C. and Kanamori, H.: A moment magnitude scale, J. Geophys. Res.-Sol. Ea., 84, 2348-2350, 1979.

Heringman, N.: The style of natural catastrophes, Huntington Libr. Q., 66, 97-133, 2003

Horleston, A., Stork, A., Verdon, J., Baird, A., Wookey, J., and Kendall, M.: Seismic monitoring of drilling operations in Balcombe, West Sussex, University of Bristol Report, Bristol, UK, 2013.

Hough, S. E.: Scientific overview and historical context of the 1811-1812 New Madrid earthquake sequence, Ann. Geophys., 47, 523-537, https://doi.org/10.4401/ag-3318 2004.

Jeffreys, H.: The rigidity of the Earth's central core, Geophysical Supplements of the Monthly Notices of the Royal Astronomical Society, 1, 371-383, 1926.

Johnston, A. C.: Seismic moment assessment of earthquakes in stable continental regions - III. New Madrid 1811-1812, Charleston 1886 and Lisbon 1755, Geophys. J. Int., 126, 314-344, 1996.

J.P.: A true and exact relation of the most dreadful earthquake which happened in the city of Naples and several other parts of that Kingdom, June the 5th, 1688: whereby about forty cities and villages were either wholly ruin'd, or extreamly damnified; eight thousand persons destroy'd and about eight hundred wounded; of which four hundred were digg'd out of the ruins, and many 
others miraculously preserved, translated from the Italian copy printed at Naples, by an eye-witness of those miserable ruins, Eyles Collection, University of Bristol Special Collections, Bristol, UK, 27 pp., 1688.

Juengel, S. J.: The Early Novel and Catastrophe, Novel, 42, 443450, https://doi.org/10.1215/00295132-2009-040, 2009.

Kahn, M. E.: The Death Toll from Natural Disasters: The Role of Income, Geography, and Institutions, Rev. Econ. Stat., 87, 271284, https://doi.org/10.1162/0034653053970339, 2005.

Kendall, J.-M., Butcher, A., Stork, A. L., Verdon, J. P., Luckett, R., and Baptie, B. J.: How big is a small earthquake? Challenges in determining microseismic magnitudes, First Break, 37, 51-56, 2019.

Keranen, K. M., Savage, H. M., Abers, G. A., and Cochran, E. S.: Potentially induced earthquakes in Oklahoma, USA: Links between wastewater injection and the $2011 \mathrm{Mw} 5.7$ earthquake sequence, Geology, 41, 699-702, 2013.

Kettlety, T., Verdon, J. P., Hampson, M., and Craddock, L.: The ML 2.9 August 2019 earthquake in Lancashire, UK, induced by hydraulic fracturing during Preston New Road PNR-2 operations, Seismol. Res. Lett., submitted, 2020.

Kircher, A.: 1678, Mundus subterraneus, Eyles Collection, GB 3 DM 1186, University of Bristol Special Collections, Bristol, UK, 2015.

LaCapra, V.: 200 years after the New Madrid earthquakes, the legends live on, available at: https://news.stlpublicradio.org/post/ 200-years-after-new-madrid-earthquakes-legends-live\#stream/ 0 (last access: 24 July 2019), 2011.

Lakoff, G. and Johnson, M.: Metaphors we live by, University of Chicago press, Chicago, Illinois, USA, 2008.

Lecocq, T., Hicks, S. P., Van Noten, K., van Wijk, K., Koelemeijer, P., De Plaen, R. S., Massin, F., Hillers, G., Anthony, R. E., and Apoloner, M.-T.: Global quieting of high-frequency seismic noise due to COVID-19 pandemic lockdown measures, Science, 369, 1338-1343, https://doi.org/10.1126/science.abd2438, 2020.

Lehmann, I.: "P", Publications du Bureau Central Séismologique International, Série A, 87-115, 1936.

Lin, Y., Michel, J.-B., Aiden, E. L., Orwant, J., Brockman, W., and Petrov, S.: Syntactic annotations for the Google Books Ngram Corpus, Proceedings of the ACL 2012 System Demonstrations, 8-14 July 2012, Jeju Island, Korea, 2012.

Mallet, D.: The Excursion: A Poem, J. Walthoe, London, UK, 1728.

McKenzie, D.: Plate tectonics and its relationship to the evolution of ideas in the geological sciences, Daedalus, 1, 97-124, 1977.

Mears, N.: Public worship and political participation in Elizabethan England, J. Brit. Stud., 51, 4-25, 2012.

Mohorovičić, A.: Earthquake of 8 October 1909 (translation), Geofizika, 9, 3-55, 1910.

Mortimer, B., Rees, W. L., Koelemeijer, P., and NissenMeyer, T.: Classifying elephant behaviour through seismic vibrations, Curr. Biol., 28, R547-R548, https://doi.org/10.1016/j.cub.2018.03.062, 2018.

Neilson, G., Musson, R., and Burton, P.: The "London" earthquake of 1580, April 6, Eng. Geol., 20, 113-141, 1984.

Nichols, R.: Re-evaluating the effects of the 1755 Lisbon Earthquake on Eighteenth-Century Minds: How Cognitive Science of Religion Improves Intellectual History with Hypothesis Testing Methods, J. Am. Acad. Relig., 82, 970-1009, https://doi.org/10.1093/jaarel/lfu033, 2014.
Oil and Gas Authority: Traffic light monitoring system (shale gas and fracking), available at: https://www.gov.uk/government/publications/ traffic-light-monitoring-system-shale-gas-and-fracking (last access: 30 October 2020), 2013.

Oldham, R. D.: The Constitution of the Interior of the Earth, as Revealed by Earthquakes, Quaterly Journal of the Geological Society, 62, 456-466, https://doi.org/10.1144/GSL.JGS.1906.062.01-04.21, 1906.

Oreskes, N.: The rejection of continental drift: Theory and method in American earth science, Oxford University Press, Oxford, UK, 1999.

Passannante, G.: The art of reading earthquakes: on Harvey's wit, Ramus's method, and the Renaissance of Lucretius, Renaissance Quart., 61, 792-832, 2008.

Paté, A., Boschi, L., Dubois, D., Le Carrou, J.-L., and Holtzman, B.: Auditory display of seismic data: On the use of experts' categorizations and verbal descriptions as heuristics for geoscience, J. Acoust. Soc. Am., 141, 2143-2162, 2017.

Penna, A. N. and Rivers, J. S.: Natural disasters in a global environment, John Wiley \& Sons, Hoboken, New Jersey, USA, 2013.

Ponton, M.: Earthquakes and Volcanoes: Their History, Phenomena, and Probable Causes, T. Nelson and sons, Nashville, Tennessee, USA, 1872.

Pratt, T. L., Horton Jr., J. W., Muñoz, J., Hough, S. E., Chapman, M. C., and Olgun, C. G.: Amplification of earthquake ground motions in Washington, DC, and implications for hazard assessments in central and eastern North America, Geophys. Res. Lett., 44, 12150-12160, 2017.

Prewitt, K. W.: Gabriel Harvey and the practice of method, Stud. Eng. Lit.-1500, 39, 19-39, 1999.

raspberryshake.net: RS StationView, available at: https: //raspberryshake.net/stationview/\#, last access: 26 May 2020.

Redmayne, D.: Mining induced seismicity in UK coalfields identified on the BGS National Seismograph Network, Geological Society, London, Engineering Geology Special Publications, 5, 405-413, 1988.

Richter, C.: An instrumental Earthquake Magnitude Scale, B. Seismol. Soc. Am., 25, 1-32, 1935.

Ringing For England: Famous Bells, available at: http:// ringingforengland.co.uk/all-bells/bell-ringing-famous-bells, last access: 24 July 2019.

Schultz, R., Wang, R., Gu, Y. J., Haug, K., and Atkinson, G.: A seismological overview of the induced earthquakes in the Duvernay play near Fox Creek, Alberta, J. Geophys. Res.-Sol. Ea., 122, 492-505, 2017.

Seed, H., Romo, M., Sun, J., Jaime, A., and Lysmer, J.: The Mexico earthquake of September 19, 1985 - Relationships between soil conditions and earthquake ground motions, Earthq. Spectra, 4, 687-729, 1988.

Taylor, C. and Dewsbury, B. M.: On the problem and promise of metaphor use in science and science communication, Journal of Microbiology \& Biology Education, 19, 1-5, https://doi.org/10.1128/jmbe.v19i1.1538, 2018.

Thomas, S.: The Earthquake in Romeo and Juliet, Mod. Lang. Notes, 64, 417-419, 1949.

Totaro, R.: Meteorology and Physiology in Early Modern Culture: Earthquakes, Human Identity, and Textual Representation, Routledge, London, UK, 2017. 
Towerbells.org: Great Bells - British Isles, available at: http://www. towerbells.org/data/GBGreatBells.html, last access: 24 July 2019.

Trempler, J.: Catastrophes and their images: Event and pictorial act, Res: Anthropology and Aesthetics, 63, 201-214, 2013.

Twyne, T.: A Shorte and Pithie Discourse, Concerning the Engendring, Tokens, and Effects of All Earthquakes in Generall: Particularly Applyed and Conferred with that Most Strange and Terrible Worke of the Lord in Shaking the Earth, Not Only Within the Citie of London, But Also in Most Partes of All Englande: Vvhich Hapned Vpon VVensday in Easter Weeke Last Past, which was the Sixt Day of April, Almost at Sixe a Clocke in the Euening, in the Yeare of Our Lord God. 1580. Written by TT the 13. of April. 1580, [John Charlewood for] Richarde Iohnes, London, UK, 1580.

USGS: M $7.5-70 \mathrm{~km} \mathrm{~N}$ of Palu, Indonesia, available at: https://earthquake.usgs.gov/earthquakes/eventpage/us1000h3p4/ executive (last access: 13 March 2020), 2018.

USGS Science Center: Earthquake Magnitude, Energy Release and Shaking Intensity, available at: https: //www.usgs.gov/natural-hazards/earthquake-hazards/science/ earthquake-magnitude-energy-release-and-shaking-intensity? qt-science_center_objects=0\#qt-science_center_objects, last access: 21 April 2020.
Voltaire and Fleming, W. F.: The Lisbon Earthquake, New Engl. Rev., 26, 183-193, 2005.

Williams, L., Macnaghten, P., Davies, R., and Curtis, S.: Framing "fracking": Exploring public perceptions of hydraulic fracturing in the United Kingdom, Public Underst. Sci., 26, 89-104, https://doi.org/10.1177/0963662515595159, 2017.

Wilson, M. P., Davies, R. J., Foulger, G. R., Julian, B. R., Styles, P., Gluyas, J. G., and Almond, S.: Anthropogenic earthquakes in the UK: A national baseline prior to shale exploitation, Mar. Petrol. Geol., 68, 1-17, https://doi.org/10.1016/j.marpetgeo.2015.08.023, 2015.

Winchilsea, H. F.: True and Exact Relation of the Late Prodigious Earthquake \& Eruption of Mount Ætna, Or, Monte-Gibello: As it Came in a Letter Written to His Majesty from Naples by the Right Honorable the Earle of Winchilsea...: Together with a More Particular Narrativ, Printed, by Benjamin Tooke... and are to be sold by Samuel Dancer, 1669.

Woodhouse, J., Rene, J. C., Hall, C. S., Smith, L. T. W., King, F. H., and McClenahan, J. W.: The Dynamics of a Ringing Church Bell, Advances in Acoustics and Vibration, 2012, 1-19, https://doi.org/10.1155/2012/681787, 2012.

Young, G.: Sonic Geography of the Arctic: An Interview with John Luther Adams, Musicworks, 70, 38-41, 1998. 